\title{
New non-destructive method for testing the strength of cement mortar material based on vibration frequency of steel bar: Theory and experiment
}

\author{
Hao Shi ${ }^{a, c}$, Lei Song ${ }^{\text {a,*, Wenlong Chen }}{ }^{\mathrm{b}}$, Houquan Zhanga, Guozhu Wanga, \\ Guotao Yuan ${ }^{\text {, Wenliang Zhang }}{ }^{\text {, Guiwu Chen }}{ }^{\text {, }}$ Yu Wanga , Gang Lin ${ }^{a}$

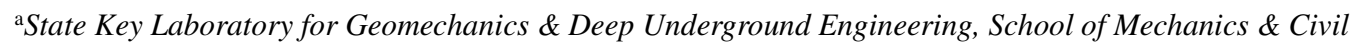 \\ Engineering, China University of Mining and Technology, Xuzhou 221116, People's Republic of China \\ ${ }^{\mathrm{b} S}$ chool of Water, Energy and Environment, Cranfield University, Cranfield MK43 OAL, UK \\ ${ }^{\mathrm{c}}$ GeoEnergy Research Centre, University of Nottingham, Nottingham NG7 2RD, UK \\ ${ }^{1}$ *Corresponding authors at: State Key Laboratory for Geomechanics \& Deep Underground Engineering, School of \\ Mechanics \& Civil Engineering, China University of Mining and Technology, Xuzhou 221116, People's Republic \\ of China E-mail addresses: songlei cumt@163.com (L. Song).
}

\begin{abstract}
Timely and accurately obtaining the strength of pouring material, e.g., concrete, cement mortar, is of great significance for engineering construction. In this paper, a non-destructive, economical and accurate strength detection method that suites for on-site using is proposed for the steel bar cement mortar material. The method based on the relationship between the vibration frequency of the steel bar and the properties of the mortar material, which is obtained by solving the Euler-Bernoulli beam problem. Both Particle Flow Code (PFC) software simulation (calibrated) and Split Hopkinson pressure Bar experiment on test samples of cement mortar and steel bar were performed to verify the theoretically obtained relationship. Studies on samples of various aggregate ratio further confirmed such correspondence. Results show that the dynamic stiffness of the cement mortar material dominates the calculation of the vibration frequency of steel bar, while the combined effect of the density, length, elastic modulus, inertia moment of the steel bar can be safely ignored. A single-valued mapping relation exists in between the dynamic stiffness coefficient and the Uniaxial Compressive Strength (UCS) of the cement mortar sample, i.e., increased dynamic stiffness coefficient with increasing UCS. Both experimental and predicted results showed a linear relationship between the vibration frequency of the steel bar and the strength of the mortar material. Fitted linear relations were proposed with coefficients depending on sample size and aggregate ratio and might serve as a good indicator for the strength of the mortar material. Further studies on the effect of internal defects of the mortar materials as well as on samples of more size and aggregate ratio are required to make the proposed method a practical tool.
\end{abstract}

Keywords: Cement mortar material; Vibration frequency of steel bar; Strength detection; Theory and experiment; Aggregate ratio 


\begin{tabular}{|c|c|c|c|}
\hline \multicolumn{4}{|c|}{ List of symbols } \\
\hline CMSD & Cement mortar strength detection & $\varepsilon_{1}$ & Axial strain \\
\hline$L$ & The length of steel bar & $\sigma_{\mathrm{p}}$ & Strength \\
\hline$y$ & $\begin{array}{l}\text { The lateral displacement of the cross } \\
\text { section of the steel bar }\end{array}$ & $\begin{array}{l}\mathrm{C} 1, \mathrm{C} 2 \\
\mathrm{C} 3, \mathrm{C} 4\end{array}$ & Undetermined constants \\
\hline$A$ & The cross-sectional area of steel bar & $\rho$ & The density of steel bar \\
\hline$E$ & The elastic modulus of steel bar & $b$ & $\begin{array}{l}\text { An undetermined constant related to the } \\
\text { variable } y\end{array}$ \\
\hline$J$ & $\begin{array}{l}\text { The inertia moment of the cross-section to } \\
\text { The neutral axis of the steel bar }\end{array}$ & $\omega$ & $\begin{array}{l}\text { The angular frequency of the micro } \\
\text { element }\end{array}$ \\
\hline$q$ & $\begin{array}{l}\text { The linearly distributed load on the micro } \\
\text { element of the steel bar }\end{array}$ & $Q$ & $\begin{array}{l}\text { The shear force on the micro element of } \\
\text { the steel bar }\end{array}$ \\
\hline$\varphi$ & The phase angle of the micro element & $Y$ & An equation related to the variable $y$ \\
\hline$M$ & $\begin{array}{l}\text { The bending moment on the micro } \\
\text { element of steel bar }\end{array}$ & $k$ & $\begin{array}{l}\text { The dynamic stiffness coefficient of } \\
\text { cement mortar }\end{array}$ \\
\hline$\lambda$ & An variable related to steel bar frequency & $i$ & The modes of steel bar frequency \\
\hline$x$ & The distance of from the coordinate origin & $f$ & Vibration frequency \\
\hline$\sigma_{1}$ & Axial stress & UCS & Uniaxial compressive strength \\
\hline
\end{tabular}

\section{Introduction}

Concrete and cement mortar are common materials in civil constructions [1-3], with advantages in high strength, durability, convenient pouring and economic cost. In combination with steel bars [4], they are widely used as load-bearing members of buildings. For both the cement mortar and concrete material, it is necessary to precisely acquire their temporal strength growth after pouring, to prepare for the next construction operation. Moreover, for large-volume components in the harsh construction conditions, e.g., the seabed, and cold and arid regions [4-6], there is highly likely a great difference in surface and internal strength [7]. Such strength variation introduces great safety hazards to the construction of the project. This has casted a requirement for a method that can detect the strength at different positions of the components both conveniently and effectively.

At present, the following five methods are commonly used to detect the strength of cement mortar or concrete materials. i) Cube compressive strength testing method [8-11]. In this method, a cube test sample is prepared using the freshly mixed material and maintained to a designed age. The sample is then tested with a pressure machine to obtain its strength. Due to the variation in maintenance conditions and the limited size of the test samples, the strength data obtained with this method is unable to precisely reflect the real-time strength of the poured structure. Moreover, the aggregate ratio used in different structures of the building shows a large variance, which significantly increases the workload. ii) Core drilling method [12-16]. This method detects the strength of the structure after the material is hardening with a cylindrical core sample drilled from the maintained structure. Although it gives an accurate assessment of the strength of the material, the method is rarely used in application for the permanent damage caused to the structure. iii) Rebound method [17-21]. This method takes advantage of the relationship between surface hardness and compressive strength of the material to quickly assess the strength of the hardened structure without damaging the structure [17-21]. However, this method can only measure the surface quality of the structure [18-25]. iv) Electro-mechanical impedance method [26-27]. This method uses the electro-mechanical properties of piezoelectric materials to detect the local strength of the structure [26-27]. Piezoelectric sensors generate stress in response to an alternating voltage which leads to the vibration of the structure when its pasted on the surface or buried inside the structure. The local vibration information of the structure is then analyzed to detect structural strength and health [2729]. However, the complexity of the method arises from the signal recognition as minor damage or 
strength changes in the components causing fuzzy changes in the signal [27,29-32]. A reasonable assessment is impossible in the absence of multiple peaks in impedance signature, which increases the operational difficulty of this method and limits its application in large concrete structures [30$32]$. v) Ultrasonic method [2,33-34]. This method relates the strength of the cast material with its ultrasonic propagation characteristics [33-34]. Parameters such as concrete compactness, uniformity, fissure depth, and surface damage layer thickness can be detected with this technique [35-37]. However, the acoustic velocity is sensitive to cement type, coarse aggregate particle size, and aggregate mixture ratio, which may affect the accuracy of measurement results [35-38]. Moreover, the detection result only registers the average value within the detection range and cannot specify the strength of a certain location [35,38-39].

The shortcomings of current strength evaluation methods of casting materials $[2,8,13,17$ $32,35,38-39]$ have posed an urgent need to explore more advanced and non-destructive detection methods. In engineering construction, pouring materials are often mixed with steel bars. One possibility is to use a certain characteristic of the steel bar to detect the strength of the cement mortar. Recent studies [34,40-41] show that the vibration characteristics of steel bars as effective sensing elements are closely related to the constraints. The question is then how well is the correspondence between the vibration frequency of steel bar and the strength of the pouring material. How does the characteristics of mortar cement, e.g., cement size, aggregate ration and curing time, affect this correspondence. This paper aims to address these questions.

In this paper, cement mortar with good homogeneity was selected as the research object. The vibration equation of steel bar in cement mortar was derived, and the correspondence between the vibration frequency of steel bar and the strength of mortar material was analytically obtained. Next, the mixed material test samples of cement mortar and steel bar was tested and compared with the theoretical formula. The influence of aggregate ratios was also investigated by testing another two samples with different aggregate ratios.

\section{Theory of cement mortar strength detection (CMSD)}

\subsection{Mechanical model of CMSD}

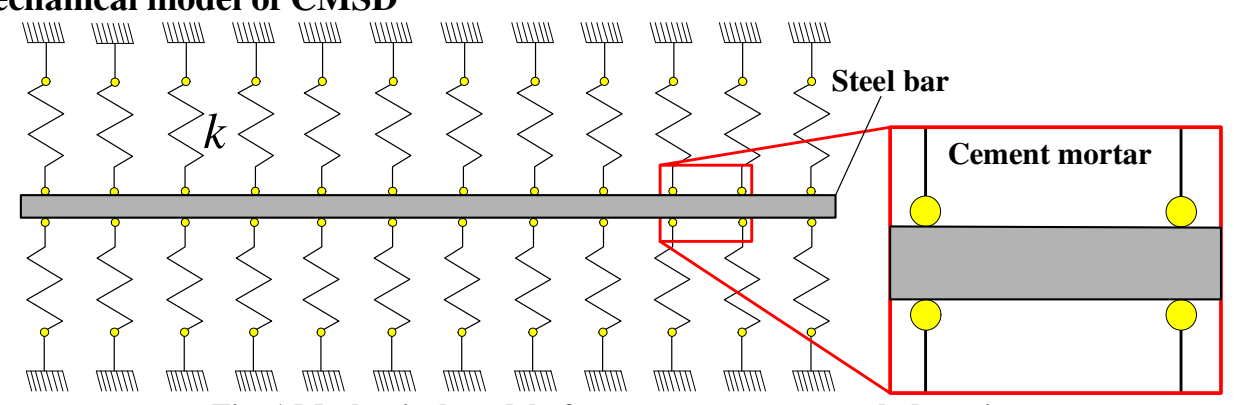

Fig. 1 Mechanical model of cement mortar strength detection.

Steel bar-cement mortar or steel bar-concrete is a good compressive and shear resistant composite material and is thus widely used in construction. The transverse vibration of the steel bar inside the cement mortar or concrete material can be described by a mechanical model, as shown in Fig. 1. In this paper, cement mortar other than concrete material was chosen as the research object for its better homogeneity shown in trial experiments, which is preferable for laboratory research [42-44]. A small vibration of the steel bar will be produced when the exposed end of the steel bar is excited, which leads to a limited deformation of the cement mortar in the disturbance range [45-46]. So the effect of the cement mortar material on the steel bar is represented by an elastic element. In addition, the elastic element is in point contact with the rebar outline to ensure compressive stress instead of tensile stress to be imposed onto the cement mortar material [47]. In the initial state, the 
radial force of the rebar is kept as zero.

\subsection{Equation of coupled steel bar transverse vibration}

A horizontal axis (x) is set along with the steel bar, and is positively rightward with the left end to be the origin, i.e., $x=0$, see Fig. 2. Subjected to a slight transverse vibration, the lateral displacement of the cross section of the steel bar at a distance of $x$ from the origin at time $t$ is defined as $y(x, t)$. The length (inside the cement mortar), the density, the cross-sectional area, the elastic modulus and the inertia moment of the cross-section to the neutral axis of the steel bar are denoted as $L, \rho, A, E$ and $J$, respectively.

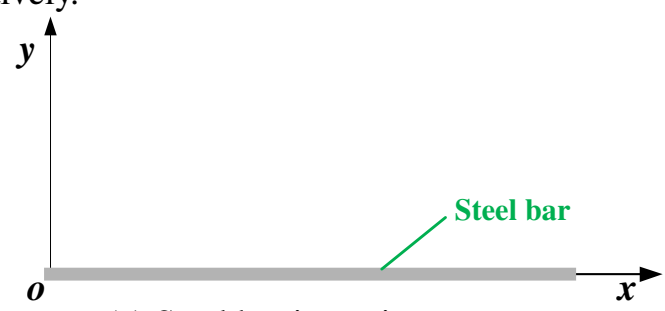

(a) Steel bar in stationary state;

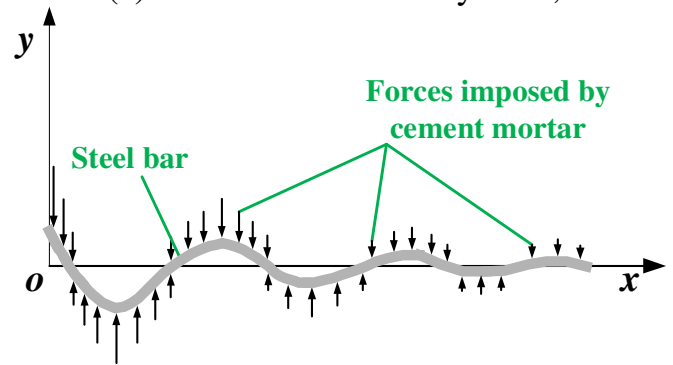

(b) Steel bar in vibrational state;

Fig. 2 Two-dimensional coordinate system of transverse vibration of steel bar.

An element of $d x$ length on the steel bar is taken for analysis. The forces on the micro element body are illustrated in Fig. 3. $q$ is the linearly distributed load with the unit of $\mathrm{N} \cdot \mathrm{m}^{-1} . Q$ and $M$ represents the shear force and bending moment at $x$, with $\frac{\partial Q}{\partial x} d x$ and $\frac{\partial M}{\partial x} d x$ being their increment. The inertial force of the element body is denoted as $\rho A d x \frac{\partial^{2} y}{\partial t^{2}}$.

The motion differential equations and the moment equilibrium conditions of the element segments in the y direction [48] require

$$
\begin{gathered}
\rho A \frac{\partial^{2} y}{\partial t^{2}}+q+\frac{\partial q}{2 \partial x} d x=-\frac{\partial Q}{\partial x} \\
\frac{\partial M}{\partial x}-\frac{\partial Q}{2 \partial x} d x-\frac{1}{12} \frac{\partial q}{\partial x} d x^{2}=Q
\end{gathered}
$$

Omitting the high-order infinitesimals in Eqs. (1) and (2) leads to

$$
\begin{gathered}
\rho A \frac{\partial^{2} y}{\partial t^{2}}+q=-\frac{\partial Q}{\partial x}, \\
\frac{\partial M}{\partial x}=Q .
\end{gathered}
$$

Substituting Eq. 4 into Eq. 3 results in, 


$$
\rho A \frac{\partial^{2} y}{\partial t^{2}}+q=-\frac{\partial^{2} M}{\partial x^{2}}
$$

where $q=-k y$, and $k$ is the dynamic stiffness coefficient of cement mortar with the unit of $\mathrm{N} \cdot \mathrm{m}^{-2}$ [4849]; the negative sign indicates that $q$ is in the opposite direction of the micro-element displacement $y$ of the steel bar. Note that $q$ is linearly distributed along the element $d x$.

With the assumption of small deformation of material mechanics, the bending moment $M$ can be expressed as $M=E J \frac{\partial^{2} y}{\partial x^{2}}$, where $J$ is the inertia moment of the steel bar section with respect to the neutral axis. The governing equation for $y$ can be obtained by introducing the expression of $M$ into Eq. (5),

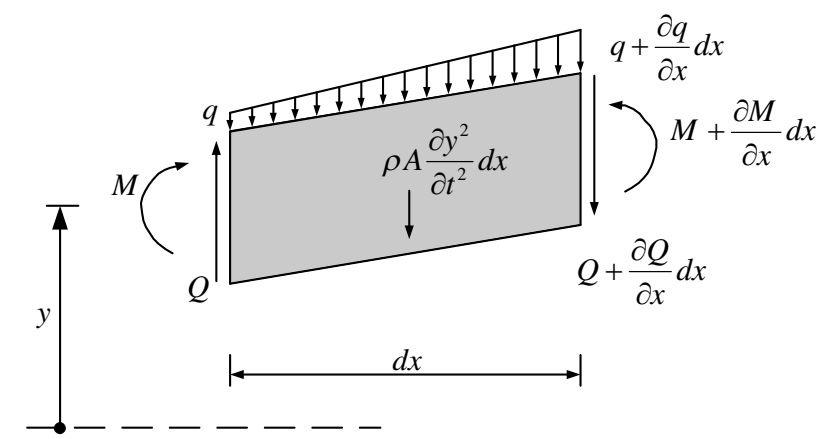

Fig. 3 Schematic diagram of the force distributed on the micro element of steel bar under transverse vibration.

$$
E J \frac{\partial^{4} y}{\partial x^{4}}+\rho A \frac{\partial^{2} y}{\partial t^{2}}+k y=0 .
$$

Applying the separation variable method [40,47], the solution of $y$ can be written as,

$$
y(x, t)=Y(x) b \sin (\omega t+\varphi),
$$

where, $Y(x)$ only represents an equation related to the displacement at the $x$ position of steel bar; the product of $Y(x)$ and a variable $b$ is the vibration amplitude-the maximum displacement at $x$ position. In addition, $\omega$ and $\varphi$ represent the angular frequency and phase angle of the micro element, respectively. The equation for $Y$ can be obtained by substituting Eq. (7) into Eq. (6),

$$
E J \frac{\partial^{4} Y}{\partial x^{4}}-\left(\rho A \omega^{2}-k\right) Y=0 .
$$

Defining $\beta_{1}^{4}=\rho A \omega^{2}-k / E J$, the Eq. (8) can be transformed into

$$
\frac{d^{4} Y}{d x^{4}}-\beta_{1}^{4} Y=0
$$

A general form of $Y$ that satisfies the Eq. (9) can be expressed as follows [34,40,47],

$$
Y(x)=C_{1} \sin \lambda_{1} x+C_{2} \cos \lambda_{1} x+C_{3} \operatorname{sh} \lambda_{2} x+C_{4} \operatorname{ch} \lambda_{2} x,
$$

where $\lambda_{1}^{2}=\sqrt{\beta_{1}{ }^{4}}=\beta_{1}^{2} ; \lambda_{2}^{2}=\sqrt{\beta_{1}^{4}}=\beta_{1}^{2} ; C_{1}, C_{2}, C_{3}$ and $C_{4}$ are undetermined constants. A relation between $\lambda$ and $\omega$ exists. In general, there are frequencies of multiple modes for the micro elements 
[34,50], which depend on its component. Here, the subscript for the frequency was used to denote the frequency of various modes, i.e., $\omega_{i}$, with $i=1,2,3 \ldots$ refers to the $i^{\text {th }}$ mode. For each frequency $\omega_{i}$, there is a corresponding $\lambda_{1, i}$. Therefore, the relationship between the transverse vibration frequency of the coupled steel bar and the dynamic stiffness coefficient of the cement mortar material at $i$ mode is obtained,

$$
f_{i}=\frac{\omega_{i}}{2 \pi}=\frac{1}{2 \pi} \sqrt{\frac{k+E J \lambda_{1, i}^{4}}{\rho A}},
$$

where $f_{i}$ refers to the ordinary frequency. In theory, the vibration frequency $f_{i}$ of the steel bar increases with the increase of the dynamic stiffness coefficient $k$. But to what extend is $k$ affecting the frequency depends on the comparative magnitude of $k$ and $E J \lambda_{1, i}^{4}$. A parameter analysis in the Eq. 11 is thus necessary.

\section{Parameter analysis of the transverse vibration frequency of steel bar}

The elastic modulus $E$, the density $\rho$, the cross-sectional area $A$ and the inertia moment of the steel bar section to the neutral axis $J$ are known properties for a specific type of steel bar. The remain unknown on the right hand side of Eq. (11) is $\lambda_{1, i}$ which corresponds to the natural frequency and the dynamic stiffness coefficient $k$ of cement mortar material.

\section{1 $\lambda_{1, i}$ corresponding to natural frequency}

It can be seen from Fig. 1 that both ends of the steel bar can be regarded as free in the coupling state of the steel bar and cement mortar material. This provides a boundary condition for Eq. (11), based on which the undetermined constants, i.e., $C_{1}, C_{2}, C_{3}$ and $C_{4}$ can be solved.

At $x=0$, the zero force and torque condition should be satisfied, i.e.,

$$
\left\{\begin{array}{l}
\left.M\right|_{x=0}=E I \times \frac{d^{2} y}{d x^{2}}=0 \\
\left.F\right|_{x=0}=E I \times \frac{d^{3} y}{d x^{3}}=0
\end{array} .\right.
$$

The same applies to boundary at $x=L$,

$$
\left\{\begin{array}{l}
\left.M\right|_{x=l}=E I \times \frac{d^{2} y}{d x^{2}}=0 \\
\left.F\right|_{x=l}=E I \times \frac{d^{3} y}{d x^{3}}=0
\end{array} .\right.
$$

The boundary conditions at both ends provide a linear group of equations for $C_{1}, C_{2}, C_{3}$ and $C_{4}$, which read

$$
\left[\begin{array}{cccc}
-\lambda_{1}^{3} & 0 & \lambda_{2}^{3} & 0 \\
0 & -\lambda_{1}^{2} & 0 & \lambda_{2}^{2} \\
-\lambda_{1}^{3} \cos \lambda_{1} L & \lambda_{1}^{3} \sin \lambda_{1} L & \lambda_{2}^{3} \operatorname{ch} \lambda_{2} L & \lambda_{2}^{3} \operatorname{sh} \lambda_{2} L \\
-\lambda_{1}^{2} \sin \lambda_{1} L & -\lambda_{1}^{2} \cos \lambda_{1} L & \lambda_{2}^{2} \operatorname{sh} \lambda_{2} L & \lambda_{2}^{2} \operatorname{ch} \lambda_{2} L
\end{array}\right]\left[\begin{array}{llll}
C_{1} & C_{2} & C_{3} & C_{4}
\end{array}\right]^{T}=\left[\begin{array}{llll}
0 & 0 & 0 & 0
\end{array}\right]^{T}
$$


Non-zero solutions of $C_{1}, C_{2}, C_{3}$ and $C_{4}$ exist only if the determinant of the coefficient matrix on the left hand side in Eq. (14) is zero. Since $\lambda_{1}^{2}=\lambda_{2}^{2}$, the following two cases are hypothesized.

(1) For $\lambda_{1}=\lambda_{2}$, the transcendental equation to satisfy the zero determinant condition is as following,

$$
\lambda_{1}^{10}\left(1-2 \operatorname{ch} \lambda_{1} L \cos \lambda_{1} L+\operatorname{ch}^{2} \lambda_{1} L-\operatorname{sh}^{2} \lambda_{1} L\right)=0 .
$$

Equation (15) can be further simplified as,

$$
\lambda_{1}^{10}\left(\cos \left(\lambda_{1} L\right) \operatorname{ch}\left(\lambda_{1} L\right)-1\right)=0,
$$

which is a typical Euler-Bernoulli beam problem. The $\operatorname{root} \lambda_{1, i}$ corresponding to the natural frequency of each order can be approximated as following,

$$
\lambda_{1, i} \approx \frac{1}{L}\left\{(2 i+1) \frac{\pi}{2}+2(-1)^{(i+1)} \exp \left(-(2 i+1) \frac{\pi}{2}\right)\right\}(\mathrm{i}=1,2,3 \ldots) .
$$

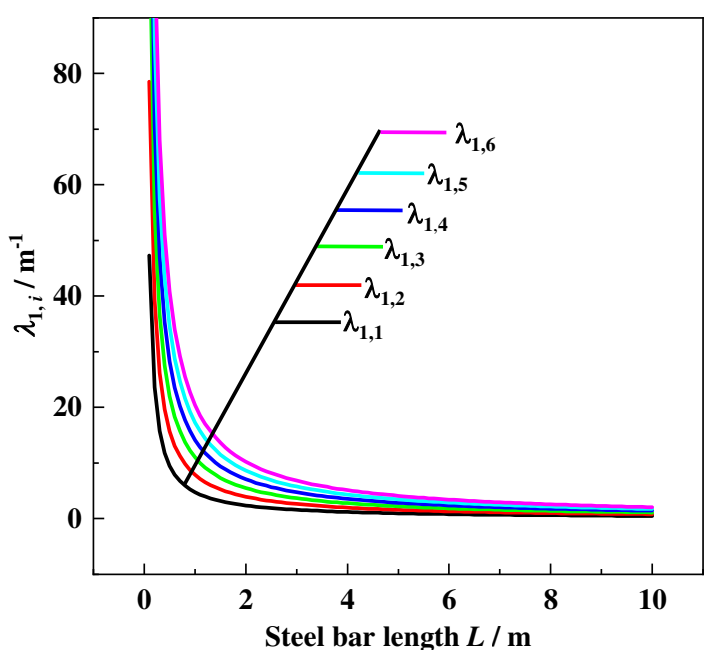

Fig. 4 The relationship between $\lambda_{1, i}$ and the steel bar length.

Theoretically, the steel bar has infinite number of natural frequencies, but in most circumstance, only low-mode natural frequencies (less than 6th mode) are concerned [45-46,50]. This is because the lower natural frequency is relatively easier to be excited. For steel bars of varying length $L$, the $\lambda_{1, i}$ from 1st to 6th mode are shown in Fig. 4 . The length of the steel bar ranges from $0.1 \mathrm{~m}$ to 10 $\mathrm{m}$.

It can be seen from Fig. 4 that all the natural frequencies quickly decrease with the increase of the steel bar length $L$, which is as expected since $\lambda_{1, i}$ is reversely proportional to the length. Furthermore, limited changes in the frequency are observed for the steel bar longer than $2 \mathrm{~m}$.

(2) For $\lambda_{1}=-\lambda_{2}$, the transcendental equation can be obtained as follows,

$$
\lambda_{2}^{10}\left(1-2 \operatorname{ch} \lambda_{2} L \cos \lambda_{2} L+\operatorname{ch}^{2} \lambda_{2} L-\operatorname{sh}^{2} \lambda_{2} L\right)=0 .
$$


Equation 18 can be converted to the following formula,

$$
\lambda_{1}^{10}\left(1-2 \operatorname{ch} \lambda_{1} L \cos \lambda_{1} L+\operatorname{ch}^{2} \lambda_{1} L-\operatorname{sh}^{2} \lambda_{1} L\right)=0 .
$$

Therefore, the solution is the same when $\lambda_{1}=\lambda_{2}$ and $\lambda_{1}=-\lambda_{2}$.

\subsection{Dynamic stiffness coefficient of cement mortar}

In this section, the cement mortar test samples were cured for various length of period, i.e., from 1 to 30 days, to obtain different strength levels. Uniaxial compression experiments were carried out on these samples and the corresponding full stress-strain curves were obtained. The Particle Flow Code in two dimensions ( $\mathrm{PFC}^{2 \mathrm{D}}$ ) numerical models were established and the mesoscopic parameters of the models were calibrated with the aid of the full stress-strain curves of the representative cement mortar test samples. Finally, the $\mathrm{PFC}^{2 \mathrm{D}}$ simulation of Split Hopkinson Pressure Bar (SHPB) experiment was performed to obtain the dynamic stiffness coefficient under different impact rates.

3.2.1 Preparation of standard samples of cement mortar
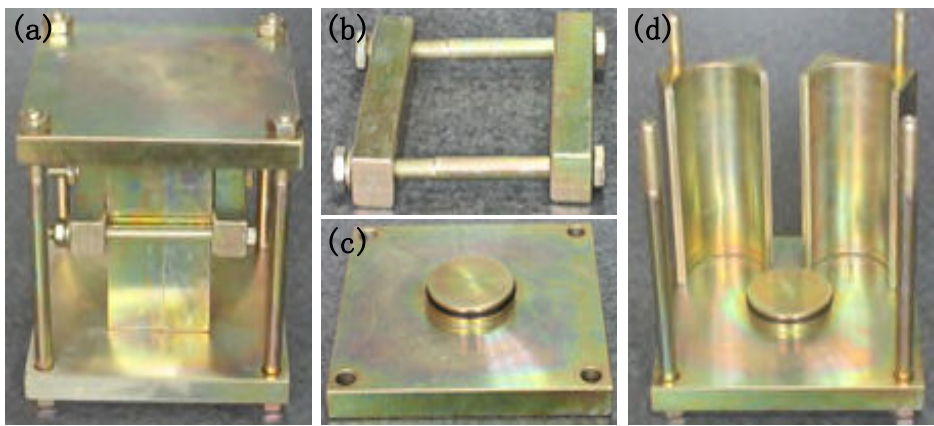

Fig. 5 Standard specimen mould and its composition [51] showing: a, mould appearance; b, horizontal hoop; c, Top plate; and d, Base plate, tiles and pillars.

The aggregate ratio used of the M25 cement mortar specimens is ( 425 cement: medium sand: water $=1: 4.03: 0.75)$ and the test sample size is (diameter $\times$ height $=50 \mathrm{~mm} \times 100 \mathrm{~mm})$. Standard specimen mould and its composition are shown in Fig. 5. There are in total 60 samples and are equally divided into 12 groups. The sample's curing time for 12 groups are 1 day, 2 days, 3 days, 5 days, 7 days, 9 days, 12 days, 15 days, 18 days, 21 days, 25 days and 30 days, respectively. Part of the samples are shown in Fig. 6.

3.2.2 Uniaxial compression experiment of cement mortar test samples

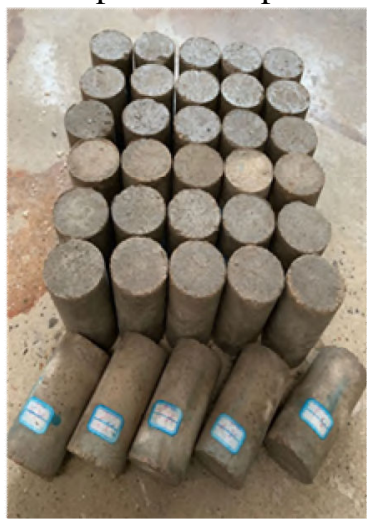

Fig. 6 Part of the cement mortar test samples.

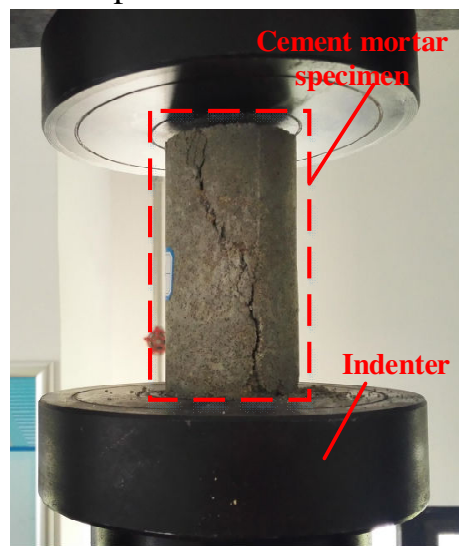

Fig.7 Uniaxial compression experiment of cement mortar test samples.

The test samples were tested following the International Society for Rock Mechanics (ISRM) testing procedures, as shown in Fig. 7. The Uniaxial Compressive Strengths (UCSs) of test samples 
in each group are listed in Table 1. It can also be seen that in each group the dispersion of test samples strength is small due to the strict control of the aggregate ratio and maintenance conditions (e.g., temperature, humidity). Note that some test samples with obvious defects have been eliminated. In each group, the sample with UCS closest to the average value is marked with *, and the corresponding test sample is selected to obtain the dynamic stiffness coefficient.

\subsubsection{Calibration of mesoscopic parameters used in $\mathrm{PFC}^{2 \mathrm{D}}$ of representative test samples}

$\mathrm{PFC}^{2 \mathrm{D}}$ was selected to simulate the dynamic stiffness coefficient of the cement mortar for its excellent performance on simulating the mechanical properties of cementitious materials [52-53]. To this end, the $\mathrm{PFC}^{2 \mathrm{D}}$ model containing 31190 particles were established. The representative test samples in Table 2 are used to calibrate the $\mathrm{PFC}^{2 \mathrm{D}}$ parameter, and the uniaxial compression experiments with same sample size (in two-dimensional), boundary conditions and loading method were reproduced. The specific parameters to be calibrated are the peak strength and elastic modulus of the sample. This is because the focus is to obtain the dynamic stiffness coefficient. Next, the "trial and error method" is used to calibrate the model parameters [54-55]. The simulated full stress-strain curves of test samples are compared with experimental results and are shown in Fig. 8. Both the elastic modulus (e.g., the marked parallel lines in Fig. 8c) and the peak strength of the simulated samples are very close to that of the corresponding experimental samples, which reflects the ability of the model to reproduce the strength and deformation characteristics of the experimental samples.

Table 1 UCSs information of test samples in each group

\begin{tabular}{|c|c|c|c|c|c|c|}
\hline \multirow{2}{*}{$\begin{array}{l}\text { Curing time } \\
\text { (days) }\end{array}$} & \multicolumn{6}{|c|}{ UCS（MPa） } \\
\hline & Sample 1 & Sample 2 & Sample 3 & Sample 4 & Sample 5 & Average UCS \\
\hline 1 & $2.84 *$ & 2.58 & 2.53 & 2.56 & 3.04 & 2.71 \\
\hline 2 & 3.93 & 3.72 & - & $3.80 *$ & 3.67 & 3.78 \\
\hline 3 & 6.03 & 6.17 & $5.53 *$ & 5.31 & 5.37 & 5.68 \\
\hline 5 & 9.21 & 9.90 & $9.27 *$ & 9.99 & 8.40 & 9.35 \\
\hline 7 & $12.01 *$ & 12.22 & 11.72 & 13.03 & 11.45 & 12.09 \\
\hline 9 & 13.45 & 15.03 & 14.65 & 16.75 & $15.01 *$ & 14.98 \\
\hline 12 & 17.13 & 17.21 & 17.67 & 18.91 & $17.77 *$ & 17.74 \\
\hline 15 & 19.12 & 22.12 & 25.02 & $23.16^{*}$ & 23.94 & 22.67 \\
\hline 18 & 22.69 & - & 23.57 & 19.85 & $21.17 *$ & 21.82 \\
\hline 21 & 19.84 & 25.02 & $24.30 *$ & 25.11 & - & 23.57 \\
\hline 25 & 25.56 & 24.88 & - & $24.51 *$ & 19.85 & 23.70 \\
\hline 30 & $24.89 *$ & 22.90 & 26.13 & - & - & 24.64 \\
\hline
\end{tabular}

* indicates that the data is closest to the average value of the group.

3.2.4 $\mathrm{PFC}^{2 \mathrm{D}}$ simulation of SHPB experiment

In this section, the SHPB experiment was reproduced using the $\mathrm{PFC}^{2 \mathrm{D}}$ model. Note that the simulation of the representative test samples had been carried out in calibrating the meso-parameters (section 3.2.3).

(1) The establishment of SHPB experiment system

The SHPB experimental system established by $\mathrm{PFC}^{2 \mathrm{D}}$ is shown in Fig. 9. The system is mainly composed of 4 parts, from left to right namely: the striker, incident bar, test sample and transmitted bar. The size of each part and the position of measuring point are marked in Fig. 9. The mesoparameters of the striker, incident bar and transmitted bar are listed in Table 2.

(2) Loading method of SHPB experiment system and data collection

The effect of different impact rates ( $v$, see Fig. 9) on the dynamic stiffness coefficient of the test samples is considered in the simulation process, owning to fact that the lateral vibration rate of the steel bar is unknown. Therefore, the speed of the striker is set to be $15 \mathrm{~m} / \mathrm{s}, 30 \mathrm{~m} / \mathrm{s}, 50 \mathrm{~m} / \mathrm{s}, 75$ $\mathrm{m} / \mathrm{s}$ and $100 \mathrm{~m} / \mathrm{s}$ in the simulation, and the striking direction has been marked in Fig. 9.

For the two-dimensional plane problem, the stress distribution of the test samples corresponds to the linearly distributed load of the micro-element in Fig. 3 [56]. Therefore, the dynamic stiffness 
coefficients of the test samples were obtained by measuring the stress and displacement parameters of a measuring element during loading, as shown in Fig. 9, where a radius of $5 \mathrm{~mm}$ in the middle of the test samples was chosen to be the measuring element.

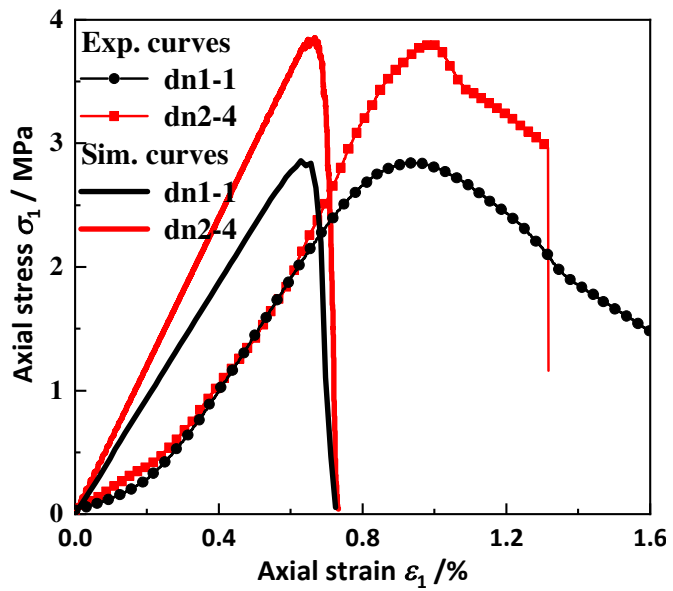

(a) Test samples dn1-1 and dn2-4;

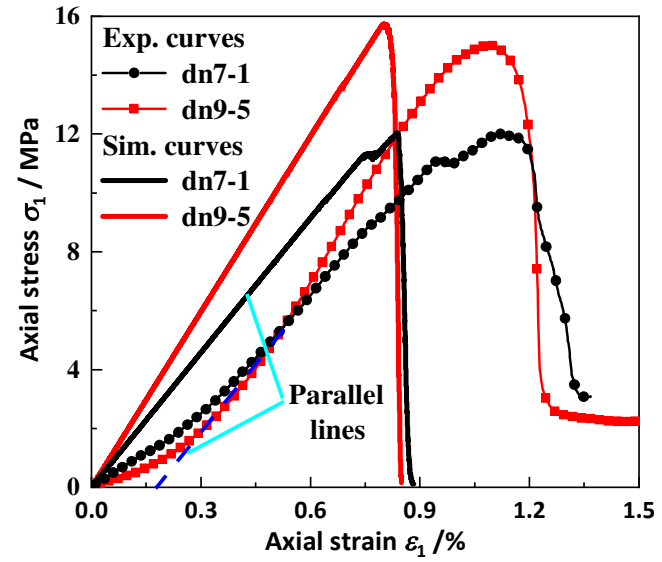

(c) Test samples dn7-1and dn9-5;

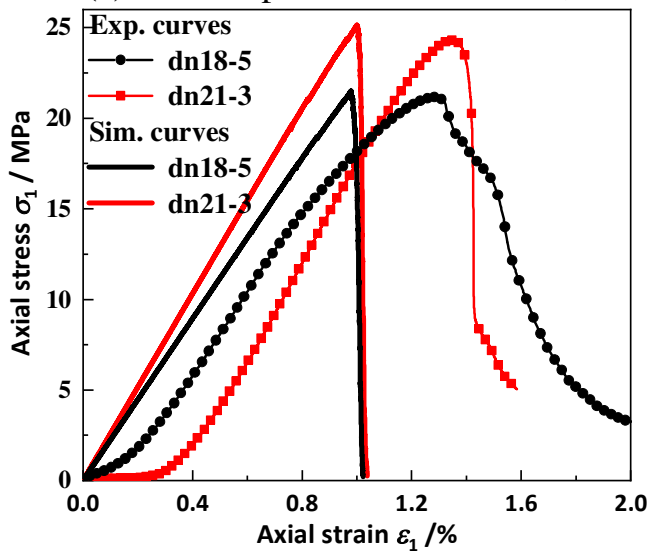

(e) Test samples dn18-5and dn21-3;

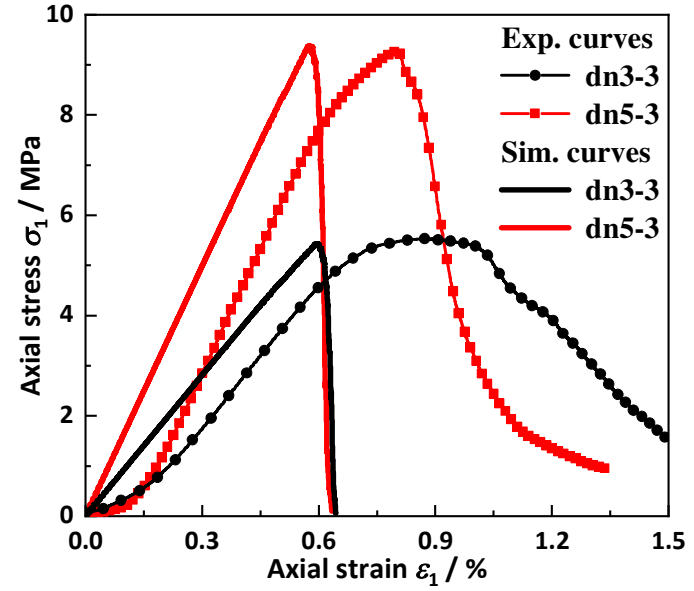

(b) Test samples dn3-3 and dn5-3;

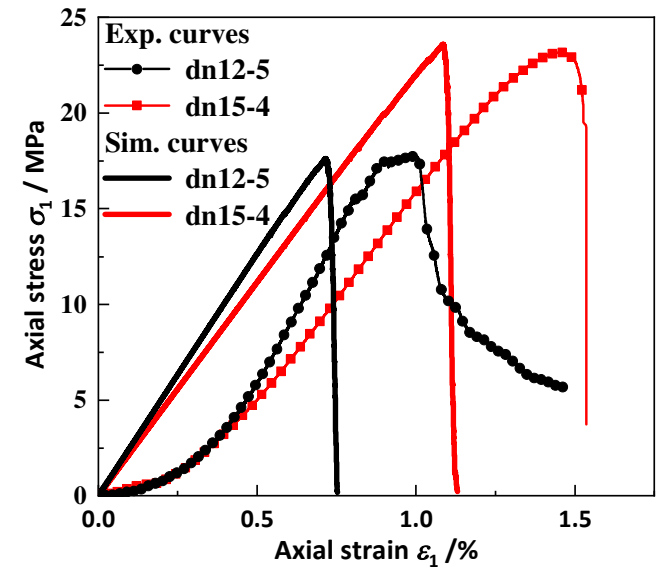

(d) Test samples dn12-5 and dn15-4;

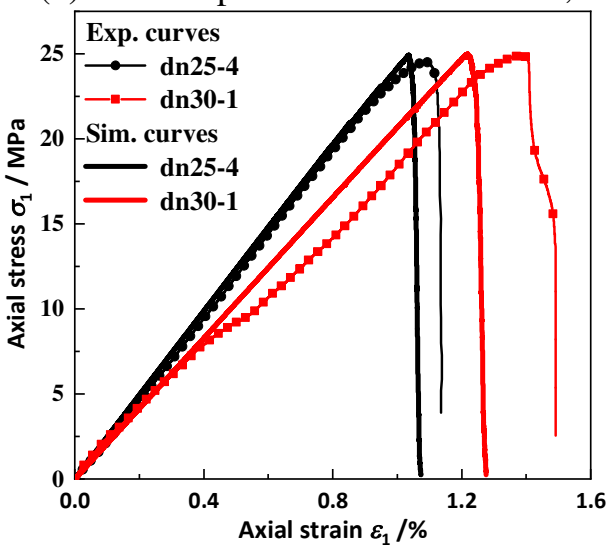

(f) Test samples dn25-4and dn30-1;

Fig. 8 Comparison between the full stress-strain curves of the simulated and experimental test samples.

(3) Stress-displacement curves of test samples

The stress-displacement curves of the representative test samples of all groups (differs in curing time, see Table 1) under different impact rates were obtained by simulating the SHPB experiment, as shown in Fig. 10. It can be seen that almost all curves are approximately linear before loading to about $0.35 \mathrm{~mm}$; but the stress-displacement curve begins to bend and the stress increase rate gradually decreases when the loading displacement is greater than about $0.35 \mathrm{~mm}$. Some exception occurs as the stress increasing rate of some specimens increased significantly in 
approaching peak stress, such as the curve of specimens of 9 days curing time. The specimen shows clear plastic deformation characteristics under dynamic load [57-60]. In general, the strength of the specimen increases with a longer curing time. The effect of curing time is reducing for curing time longer than 12 days, as shown by the merging of the stress-displacement curves of specimens with long curing time regardless the various loading rate. This means that most of the internal hydration reaction of the specimen has been completed when the curing timeis12 days. A longer curing time therefore leads to minor increase in the dynamic stiffness coefficient of the specimens [61-62], which is consistent with the strength evolution process of the specimens (see Table 1). The peak displacement, on the other hand, decreases with the increasing of curing time. This trend is not so obvious or even reversed when the curing time is longer than 21 days, with the strength of 30 days sample being weaker than that of 21 days. The abnormal weakening of the dynamic stiffness coefficient of the specimen might be due to the dispersion of the strength characteristics since the increasing strength effect of curing time longer than 21 days is trivial $[22,63]$. A same reversion in the tendency occurs for the peak displacement. The increasing impact rates leads to stronger strength and bigger peak displacement, and this applies to samples of all groups.

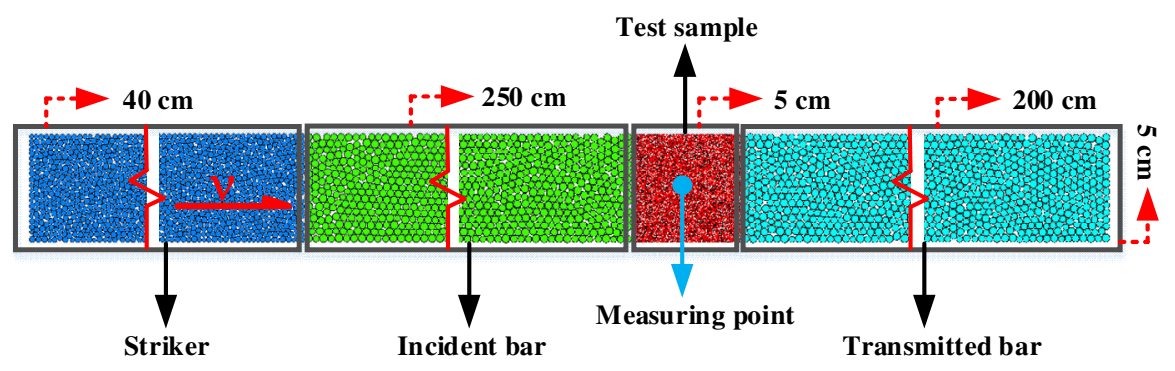

Fig. 9 SHPB experimental system established by PFC software.

Table 2 Mesoscopic parameters of the striker, incident bar and transmitted bar.

\begin{tabular}{cccc}
\hline Parameters & \multicolumn{3}{c}{ Value } \\
\cline { 2 - 4 } & Striker & Incident bar & Transmitted bar \\
\hline Minimum particle size $(\mathrm{mm})$ & 1 & 1.5 & 1.5 \\
Maximum particle size $(\mathrm{mm})$ & 1.5 & 2 & 2 \\
Density $\left(\mathrm{kg} \cdot \mathrm{m}^{-3}\right)$ & & 7850 & \\
Porosity & 0.08 & \\
Contact bond modulus $(\mathrm{GPa})$ & 210 & \\
Contact bond stiffness ratio & 1.0 & \\
Friction coefficient & & 2000 & \\
Parallel bond tensile strength $(\mathrm{MPa})$ & & 2000 & \\
Parallel bond cohesion $(\mathrm{MPa})$ & 25 & \\
Parallel bond friction angle $\left({ }^{\circ}\right)$ & & 210 & \\
Parallel bond modulus $(\mathrm{GPa})$ & & 1.0 & \\
Parallel bond stiffness ratio & & & \\
\hline
\end{tabular}

(4) Dynamic stiffness coefficient of the test samples obtained by simulation

The dynamic stiffness coefficient of the test samples is calculated by taking the slope of the stress-displacement curve (see Fig. 10). According to the analysis in section 3.2.4(3), the slope gradually decreases before the stress reaching a peak value, and even turns to negative value after the peak. The stress-displacement curve of the specimen at the peak stress bends significantly. So the slope of the secant at half of the peak stress is selected as the dynamic stiffness coefficients of the test samples [64-69], and the extracted data are present in Fig. 11. For all impact rates, the dynamic stiffness coefficient of the test samples increases with increasing curing time until 12 days, 
and stabilizes around the peak value with some flocculation. As explained in Section 3.2.4(3), when the test samples are cured for about 12 days, the internal hydration reaction has almost completed, and the strength and stiffness of the test samples increase very slowly with longer curing time [6162]. In this circumstance, the fluctuation of the strength value due to the specimen dispersion may outcompete the strength increase of longer curing time [22,63], which causes the stiffness coefficient in Fig. 11 to fluctuate when the curing time is longer than 12 days.
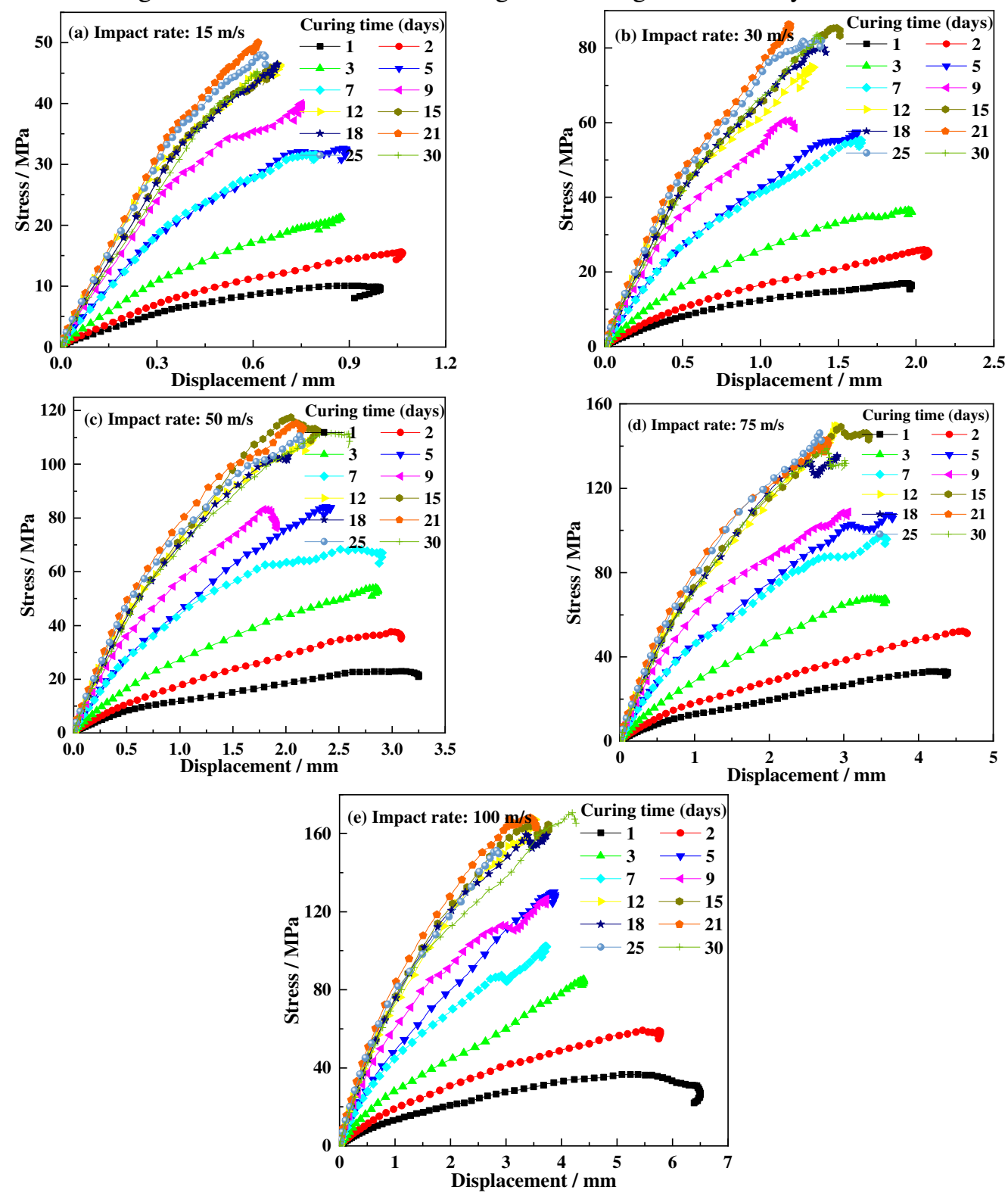

Fig.10 The stress-displacement curves of the representative test samples under different curing times and impact rates.

Furthermore, for the impact rates of $30 \mathrm{~m} / \mathrm{s}, 50 \mathrm{~m} / \mathrm{s}, 75 \mathrm{~m} / \mathrm{s}$ and $100 \mathrm{~m} / \mathrm{s}$, the curves of dynamic stiffness coefficient are very close to each other, and are significantly lower than that of 15 $\mathrm{m} / \mathrm{s}$. This is a combined result of the determination method of dynamic stiffness coefficient and the stress-displacement curves of test samples. Most of the stress-displacement curves in Fig. 10 are increasing with a constant rate (linear slope) for displacement less than $0.35 \mathrm{~mm}$ and turning to smaller rate (bending curve) for displacement bigger than $0.35 \mathrm{~mm}$ (see Fig. 10). However, for the curves of $15 \mathrm{~m} / \mathrm{s}$ impact rate, the displacement at half of the peak stress of the test samples is less than $0.35 \mathrm{~mm}$ (see Fig. 10a), resulting in relatively large dynamic stiffness coefficients; for the 
curves of greater impact rate (see Fig. 10b e), the displacements are larger than $0.35 \mathrm{~mm}$, resulting in relatively small dynamic stiffness coefficients.

(5) The influence of dynamic stiffness coefficient on vibration frequency of steel bar

The dynamic stiffness coefficient of the test samples is in the order of $10^{1} \mathrm{GPa}$ (see Fig .11). Taking steel bar with elastic modulus $E$ of $210 \mathrm{GPa}$ and diameter $d$ of $22 \mathrm{~mm}$ as an example, the product of the elastic modulus $E$ and inertia moment $J$ of the steel bar section to the neutral axis is $2.41 \mathrm{kPa}$ according to $J=\pi d^{4} / 64$ [70]. For steel bar of $0.5 \mathrm{~m}$ length, $\lambda_{1, i}$ (approximated by Eq.(17)) corresponding to 1 st mode to 6th mode are $9.46 \mathrm{~m}^{-1}, 15.7 \mathrm{~m}^{-1}, 21.99 \mathrm{~m}^{-1}, 28.27 \mathrm{~m}^{-1}, 34.56 \mathrm{~m}^{-1}$ and $40.74 \mathrm{~m}^{-1}$, respectively. The maximum value of $E J \lambda_{1,6}^{4}$ in first six modes is $6.6 \mathrm{GPa}$. For steel bar of longer length, this value is even smaller, since $\lambda_{1, i}$ is reversely proportional to $L$. So the dynamic stiffness coefficient $k$ of the cement mortar is much larger than the combination $E J \lambda_{1}^{4}$ of physical and mechanical parameters of steel bar, as long as the length of the steel bar is greater than $0.5 \mathrm{~m}$. It shows that when the length of the steel bar is greater than $0.5 \mathrm{~m}$, the dynamic stiffness coefficient of the cement mortar dominates the vibration frequency of the steel bar, whereas the combined effect of the length, elastic modulus and inertia moment of the steel bar section to the neutral axis can be reasonably ignored.

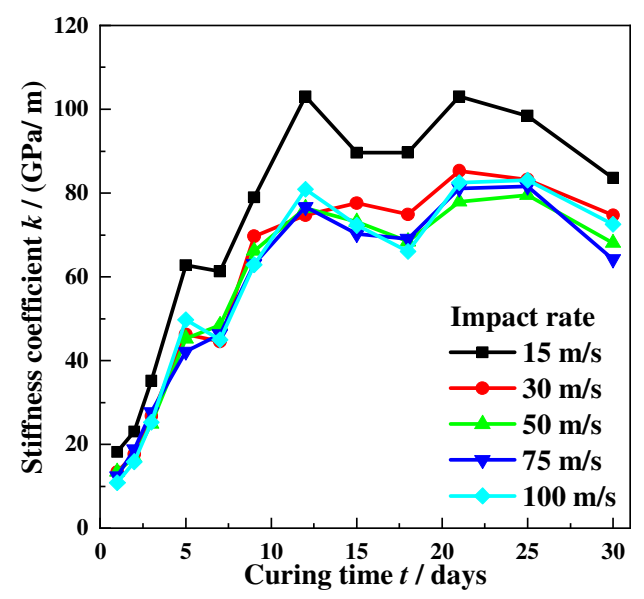

Fig. 11 Variation of the dynamic stiffness coefficient of the test samples with curing time under different impact rates.

\section{Theoretical prediction of the vibration frequency of coupled steel bar}

In principle, the prediction of the vibration frequency of coupled steel bar through Eq. (11) needs to consider both the dynamic stiffness coefficient and the combined effect of length, elastic modulus and inertia moment. The analysis in section 3.2.5 shows that the contribution from the latter effect can be neglected in most circumstances, which enables the dynamic stiffness coefficient to be the indicator for vibration frequency. Furthermore, a correspondence between the dynamic stiffness coefficient (see Fig. 11) and the strength (see Table 1) of the test samples can be established through their dependence on the curing time, as shown in Fig. 12a. Therefore, it is reasonable to relate the vibration frequency of the steel bar with the strength of the cement mortar (see Fig. 12b).

The dynamic stiffness coefficient of the test samples and the vibration frequency of the coupled steel bar have similar dependency on the test sample strength. That is, an almost linear dependency as the strength of the test samples increases to $17.5 \mathrm{MPa}$, and stabilized value with some flocculation 
as the strength is between $17.5 \mathrm{MPa}$ and $25 \mathrm{MPa}$.

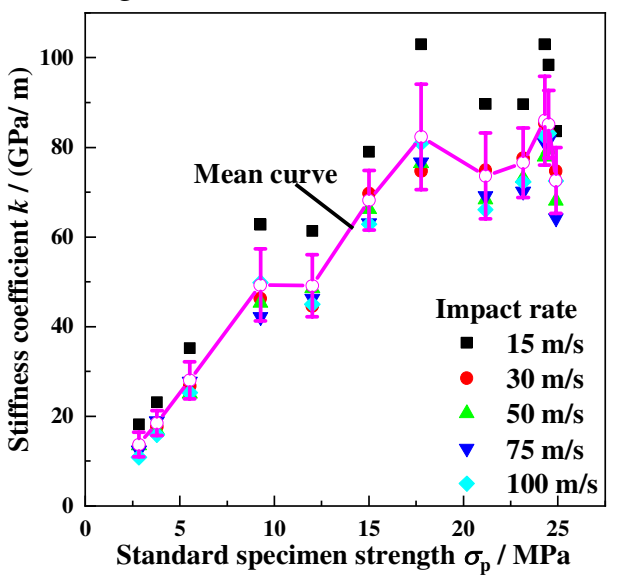

(a) Correspondence between the strength and the dynamic stiffness coefficient of the test samples;

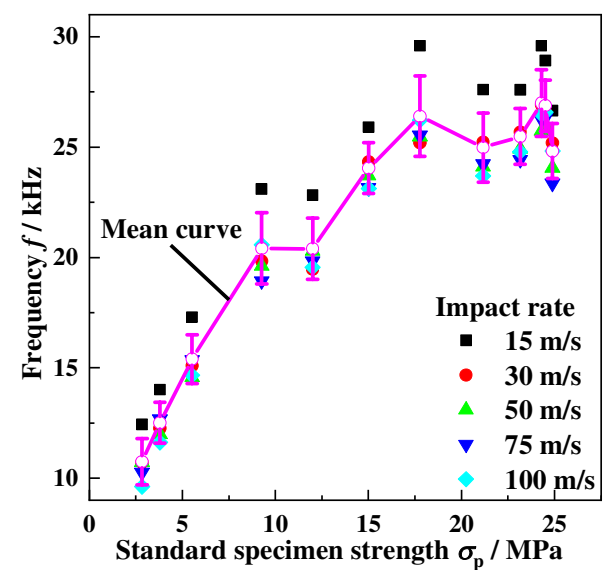

(b) Correspondence between the strength and the vibration frequency of the coupled steel bar;

Fig. 12 Correspondence between the strength and the dynamic stiffness coefficient of the test samples, the vibration frequency of the coupled steel bar.

\section{Experimental verification of the vibration frequency of coupled steel bar}

\subsection{Preparation of test samples for steel bar frequency detection}

5.1.1 Design of test sample size, aggregate ratio and signal collection point

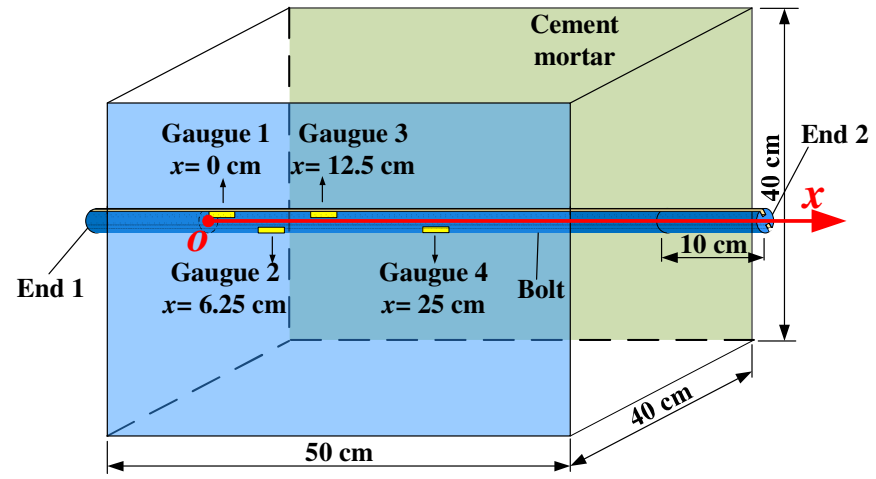

Fig. 13 Schematic diagram of the test sample for the frequency detection of the steel bar.

To verify the relationship between the vibration frequency and specimen strength obtained in Section 4, the frequency detection experiment of coupled steel bar was carried out in this section. The experimental specimen is mainly composed of 3 parts, i.e., the cement mortar body, the steel bar and the high-frequency signal acquisition components, as shown in Fig. 13. The designed size of the cement mortar body is (length $\times$ width $\times$ height $=50 \mathrm{~cm} \times 40 \mathrm{~cm} \times 40 \mathrm{~cm}$ ), with the same aggregate ratio as the uniaxial compression samples produced in Section 3.2.1. The steel bar is preembedded into the cement mortar material, and its central axis coincides with that of the cement mortar body, see Fig. 14. The steel bar has $\Phi 22$ diameter, $0.7 \mathrm{~m}$ total length and $0.1 \mathrm{~m}$ exposed length at both ends. The end 1 is used for excitation operation, and the end 2 is used for exporting the sensing component leads, compensating signal and shielding noise. The steel bar needs to be grooved on both sides. The depth and width of groove are $4.5 \mathrm{~mm}$ and $5 \mathrm{~mm}$, respectively, which is chosen to facilitate the arrangement of the sensing components. It can be seen from Fig. 14 that the $x$-axis is established along the steel bar and originates at the junction of the end 1 of the steel bar and the cement mortar body. The sensor components are arranged at $x=0 \mathrm{~cm}, 6.25 \mathrm{~cm}, 12.5 \mathrm{~cm}$ and $25 \mathrm{~cm}$. To facilitate the export of the sensor component leads, the sensor components 1 and 3 are arranged on one groove of the steel bar, whereas 2 and 4 are arranged on the other groove of the steel bar. Note that in arranging the steel bar, the connection line of the two grooves should be kept perpendicular to the bottom of the test sample. This is to ensure that when the end 1 of steel bar is 
subjected to a vertical excitation, the acquisition components are in the vibration direction, so as to accurately collect the steel bar vibration information.

\subsubsection{Pouring and curing of frequency test samples}

The strain gauge was used as the signal acquisition component. The grooved steel bar of specified length was prepared. Next, the strain gauges were attached at the corresponding positions and covered with the resin AB glue, as shown in Fig. 14 (a). The 704 silicon rubber was used to fill the grooved position of the steel bar, to protect the strain gauges and their leads during the pouring of cement mortar (see Fig. 14 (b)). Consequently, the prepared steel bar was installed to the test sample mold according to Fig. 13 while keeping the connection line of the two grooves on both sides perpendicular to the ground (see Fig. 14 (c)). The materials for casting samples were carefully mixed, and the casted test samples were polished and kept in a high moisture condition for various time duration. Note that the number of test samples for the verification experiment is 3 .

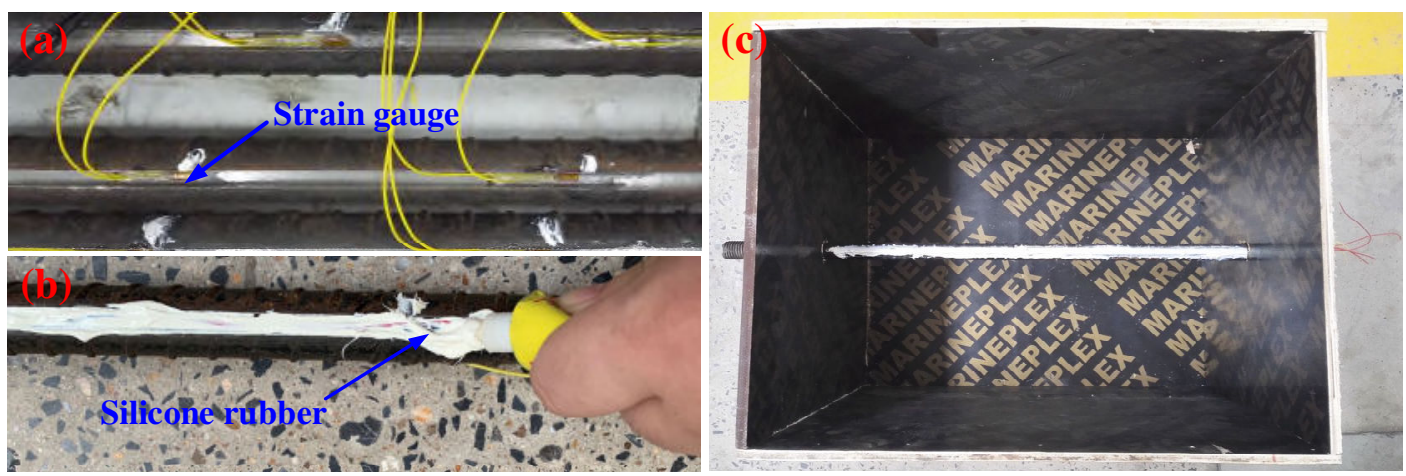

Fig. 14 Frequency test sample showing: a, strain gage attachment; $\mathbf{b}$, groove sealed by resin glue; $\mathbf{c}$, test sample mould and steel bar arrangement.

\subsection{Detection of the vibration frequency of the coupled steel bar}

5.2.1 Detection system and method of steel bar vibration frequency

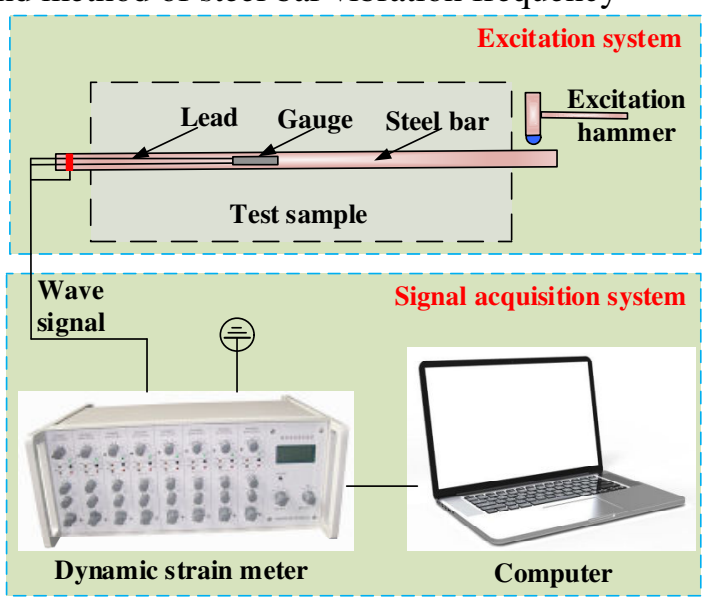

Fig. 15 Steel bar frequency detection system.

The detection system of steel bar frequency is shown in Fig. 15. The detection system is composed of a test sample, a rigid excitation hammer, an ultra-dynamic strain meter, and a computer along with necessary wires. The striking end of the hammer is made of rubber, and the maximum sampling frequency of the strain meter is $20 \mathrm{MHz}$. The sampling frequency is set to be $1 \mathrm{MHz}$. This is because the vibration frequency of the steel bar predicted (in Fig. 12) is between $10 \mathrm{kHz}$ to 30 $\mathrm{kHz}$ and the signal acquisition requires the number of measurement points to be more than 24 in each vibration cycle [71].

The signal acquisition negative delaying time $(4 \mathrm{~ms})$ and the signal acquisition duration (30 $\mathrm{ms}$ ) were set through the computer interactive interface. The acquisition channel was balanced to 
ensure that the noise caused strain change range does not exceed $\pm 100 \mu \varepsilon$. The samples were cured over designed duration periods. To excite the vibration, a hammer was used to vertically tap the end 1 of the steel bar. For each operation, i.e., vertical tapping end 1, the signal of each strain gauge was collected. This operation was repeated 3 times for each sample. The vibration information caught by the strain gauges was collected accordingly. This had been done for all 3 test samples.

5.2.2 Example of signal analysis and processing

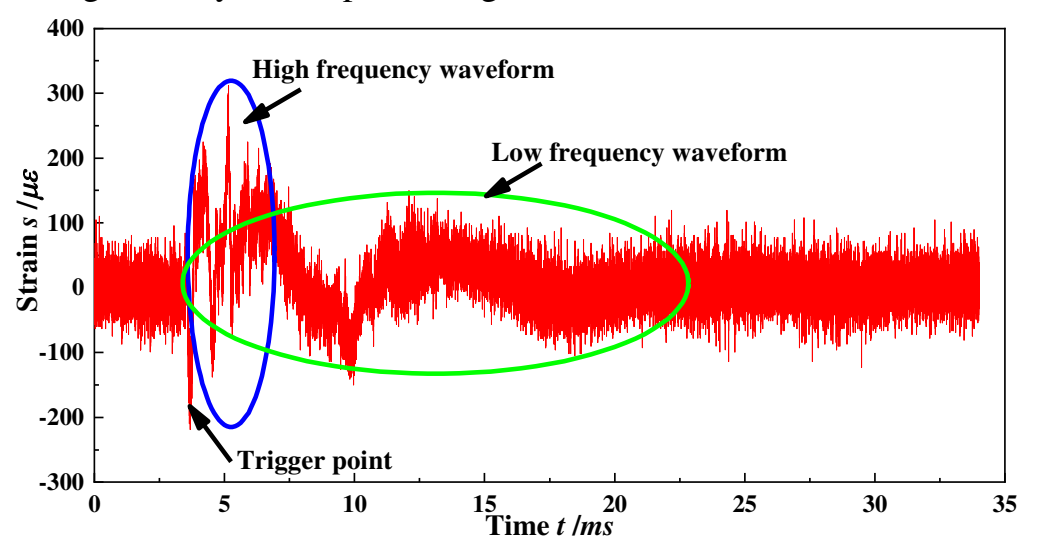

Fig. 16 The original signal of a strain gauge in test sample 1 (Curing time $=1$ day $)$.

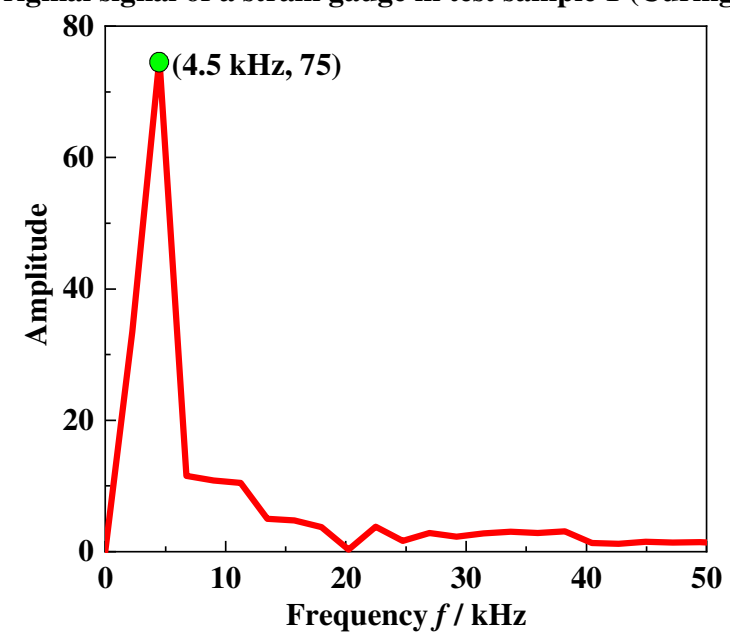

Fig. 17 The vibration frequency of the steel bar reflected by the strain gauge 4 in test sample 1 (Curing time $=1$ day).

The original signal obtained at strain gauge 4 with sample of 1 day curing time is shown in Fig. 16 as an example. The behavior of signal over time can be grouped into 3 parts, namely the highfrequency waveform (highlighted in the blue ellipse in Fig. 16) near the trigger point, the lowfrequency waveform (green ellipse in Fig. 16) and the remaining noise waveform. Both highfrequency and low-frequency waveforms decay over time, whereas the noise waveform remains relatively stable. According to the vibration characteristics analysis of metal rods by the researches of Capozucca [72] and Zhang et al [73], the high-frequency signal is recorded as the vibration frequency of the steel bar. In addition, the signal needs to be intercepted before spectrum analysis and only the signal within $2 \mathrm{~ms}$ after the trigger point is retained. This is because the signal-to-noise ratio $(\mathrm{S} / \mathrm{N})$ of the signal is highest near the trigger time [74]. The Stationary Wavelet Transform (SWT) implemented in MATLAB is recognized as an effective and convenient noise reduction algorithm, and was used to de-noise the intercepted signal with four-layer decomposition [75-80]. The vibration frequency of the steel bar at the measurement point was then obtained by applying Fourier spectrum analysis on the de-noised signal [81-85], which is present in Fig. 17. For the example specimen, the vibration frequency of the steel bar captured by the strain gauge 4 is $4.5 \mathrm{kHz}$. 


\subsubsection{Detection result of vibration frequency of steel bar}

The aforementioned frequency detection and analysis method were applied to samples of all curing time. The relation in between the obtained vibration frequency and the curing time is shown in Fig. 17. The vibration frequency of the steel bar collected at all four gauges increases with increasing curing time till 18 days. For samples of longer curing time, the vibration frequency remains almost unchanged. The vibration frequencies detected at strain gauges 2, 3 and 4 are similar and differs from that at strain gauge 1 . This indicates that the boundary effect on the vibration characteristics of the steel bar are less as the collecting point is further than $6.25 \mathrm{~cm}$ away from the end. The data of the gauge 2 is relatively volatile (as shown in Fig. 18) which is because only test sample 2 contains this measuring point.

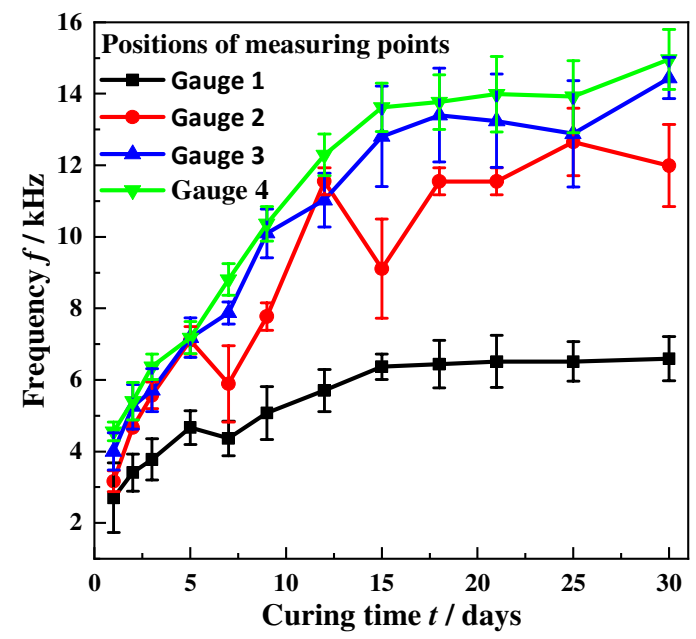

Fig. 18 Evolution of steel bar vibration frequency at different positions with curing time.

It can be seen from Fig. 18 that the boundary effect on the steel bar position corresponding to strain gauge 4 is the smallest $[34,48,86]$. Therefore, the vibration frequency obtained at gauge 4 is used for the following analysis. A relation between the vibration frequency of the steel bar and the strength of the corresponding standard samples is obtained and shown in the Fig. 19a. Note that the strength of the standard sample is approximated based on the relation of curing time and strength as listed in Table 1. In figure 19(a), the vibration frequency of the steel bar collected at the gauge 4 shows a linear dependency (with a slope of 0.46) on the strength of the standard samples, with a fitting variance of 0.991 . The size of the standard sample differs from that of the test sample, so is the strength. The scale effect of rock-like materials was used to estimate the UCS of the test sample based on that of the standard sample [87-93].

Hoek and Brown [94] proposed the size effect model to estimate the UCS of targeted sample based on the strength of a sample with $50 \mathrm{~mm}$ diameter (UCS50) using the following formula,

$$
\mathrm{UCS}=\mathrm{UCS}_{50}\left(50 / d_{\mathrm{r}}\right)^{c},
$$

where $c=0.18$ is a constant valid for various rock types [94], $d_{\mathrm{r}}$ is the diameter of targeted sample.

Zhai et al. [90] extended Eq. (20) from rock limited samples to rock-like materials such as cement mortar, and obtained the corresponding relationship between UCS and the diameter of the rock-like material by fitting the experimental data. The cross section of the frequency test sample used in this study is a square with a side length of $400 \mathrm{~mm}$, so the corresponding equivalent diameter is about $450 \mathrm{~mm}$ [95-96]. According to the research of Zhai et al. [90], the strengths of the sample with a diameter of $450 \mathrm{~mm}\left(\mathrm{UCS}_{450}\right)$ and $50 \mathrm{~mm}\left(\mathrm{UCS}_{50}\right)$ satisfies the following formula, 


$$
\mathrm{UCS}_{450}=0.49 \mathrm{UCS}_{50} \text {. }
$$

Here $C_{\mathrm{f}}=0.49$ is a fitted coefficient obtained from Zhai et al. [90] for $d_{\mathrm{r}}=450 \mathrm{~mm}$. With the aid of Eq. (21), the correspondence between the vibration frequency of the steel bar and the strength of the frequency test samples accounted for the scale effect can be obtained, and is shown in Fig. 19b. A linear relationship between the vibration frequency of the steel bar and the strength of the frequency test samples (now with a slope of 0.94) is proposed with a fitting variance of 0.991. This indicates a good correspondence between the strength of cement mortar material and the vibration frequency of the coupled steel bar. Therefore, it is concluded that the vibration frequency of steel bar can be used to retrieve the strength of cement mortar material.

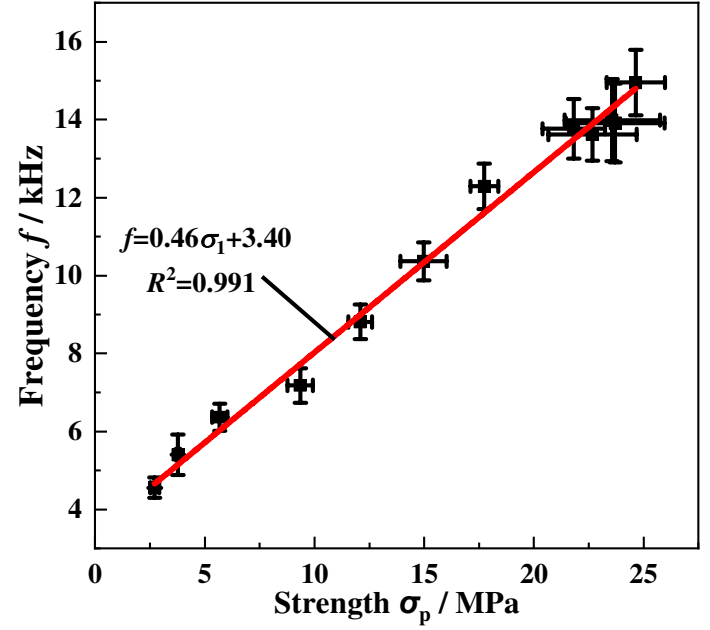

(a) The correspondence between the vibration frequency of the steel bar and the strength of the corresponding standard samples;

Fig. 19 The evolution of the vibration frequency of the steel bar reflected by the strain gauge 4 with the curing time.

\subsection{Comparative analysis of the experiment and prediction results}

To check if the frequency calculated with Eq. (11) can represent the natural frequency, the prediction results need to be compared with the experimental results. Note that only the contribution from the dynamic stiffness in Eq. (11) is considered for reasons discussed in previous sections. The vibration data collected at strain gauge 4 set was selected for the comparison for it's the least affected data set by the boundary. For various impact rates, the calculated dynamic stiffness is different (see Fig. 11) and so is the predicted results. Here the average value was used for comparison. Owing to the size variance, the strength and stiffness of the standard test sample and that of the frequency test samples are different, so they cannot be directly compared. Here, the parameters of the standard test samples and the corresponding predicted frequency are presented as a reference. The experimental results are scaled using the Eq. (21) and the correspondence between frequency and strength is shown in Fig. 19b. The specific steps are as follows: Firstly, convert the strength of the frequency test sample into the strength of the standard specimen using Eq. (21); then calculate the corresponding frequency value according to the frequency-strength relationship fitted in Fig. 19b; finally, use the strength of the frequency test sample as the intermediate variable to establish the relationship between the frequency and the curing time.

The dependency of frequency on the curing time and the strength of test samples are present in Fig. 20 for both the scaled experimental and the prediction results. The predicted frequency of 
steel bar ranges from $10 \mathrm{kHz}$ to $27 \mathrm{kHz}$, while the scaled experimental frequency ranges roughly from $5 \mathrm{kHz}$ to $27 \mathrm{kHz}$. Over all, the predicted frequency results are slightly larger than the scaled experimental results, especially for samples of weak strength or with short curing time. This indicates that the size effect is sensitive to the curing time of the samples. In general, the dependency the steel bar vibration frequency obtained by experiment and prediction on the curing time and the strength follow the same trend.

For the samples with curing period of less than 15 days, the predicted and the scaled experimental results both increases with increasing curing period but at a reducing rate; for samples of longer curing period, the change of both predicted and experimental vibration frequency are very small (see Fig. 20a). The scaled experimental frequency is linearly dependent on the sample strength (see Fig. 20b), whereas the predicted results flocculate around the experimental results with higher value for small strength and lower value for strong strength. For the convenience of simulation, the test sample with the UCS closest to the average UCS of each group was selected for the prediction study (see section 3.2.2). As a result, the UCS data in the prediction is very single (the data marked with *, see Table 1). On the other hand, the strength dispersion of the cement mortar test sample is relatively large. The vibration frequency evolution of the steel bar obtained by prediction can be fairly considered as consistent with the experimental results.

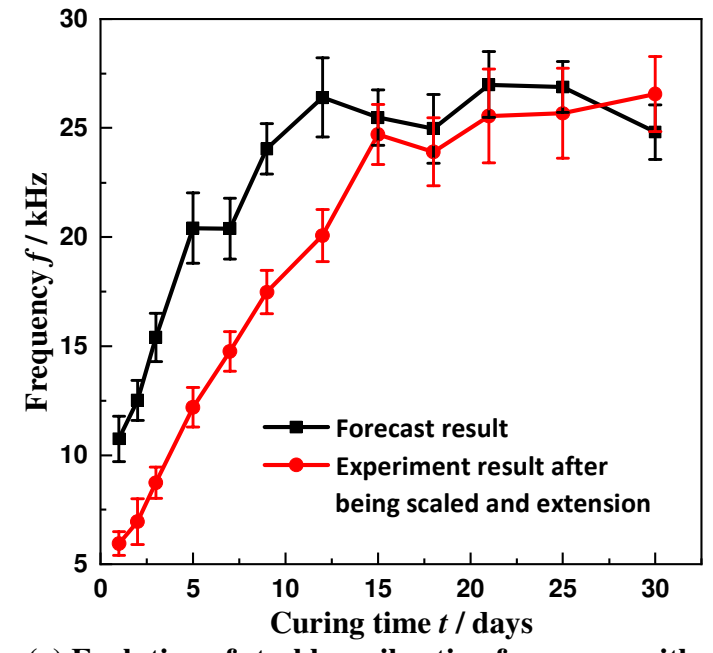

(a) Evolution of steel bar vibration frequency with curing time of test sample;

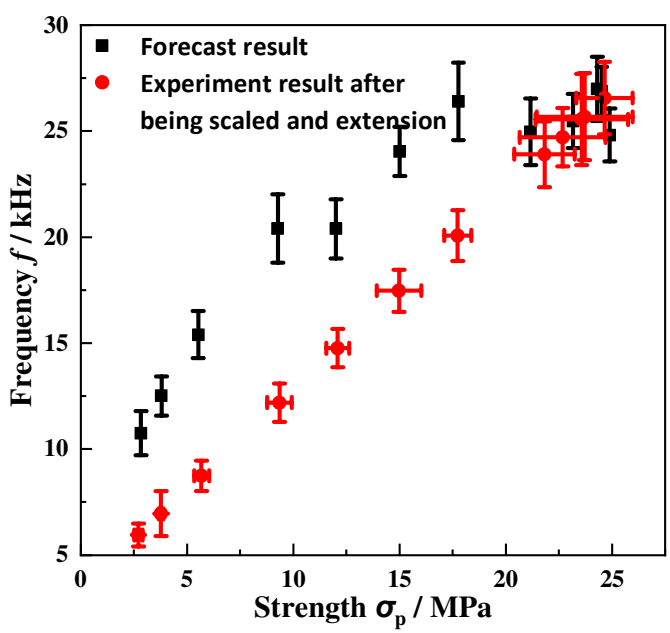

(b) Evolution of steel bar vibration frequency with strength of test sample;

Fig. 20 Comparison of the predicted and the experimental results of steel bar vibration frequency.

\subsection{Influence of cement mortar aggregate ratio on vibration frequency of steel bar}

Two additional test samples with cement mortar grades M30 and M15 were made to investigate the influence of cement mortar aggregate ratio (in the rest samples in Fig. 14(f)). The aggregate ratio of M30 cement mortar is (425 cement: medium sand: water $=1: 3.37: 0.77$ ), and that of M15 cement mortar material is (425 cement: medium sand: water $=1: 4.71: 0.94$ ). The size, curing time, frequency detection and analysis method of the test samples are the same as the verification test. There is only one measuring point on each test sample which is located on the middle of the sample, i.e., $x=25 \mathrm{~cm}$. The corresponding vibration frequency was obtained through the same procedure as in Section 5.2. For the above two types of aggregate ratio, the test samples with the standard size used in section 3.2.1 were also prepared and their UCSs of different curing times were obtained.

In conjunction with Section 5, there are 3 types of steel bar frequency test samples with cement mortar grades of M15, M25 and M30 made in this paper. And the vibration frequency of the steel bar collected at the middle of the samples is present as a function of curing time, as shown in Fig. 
21. The dependency of the steel bar frequency on the curing time for various strength grade shows similar trend, i.e., with increasing frequency for longer curing time, but with reduced increasing rate. Moreover, a higher strength grade of cement mortar leads to higher frequency, which is agreed with the finding that the vibration frequency of the steel bar increases with the strength of the cement mortar.

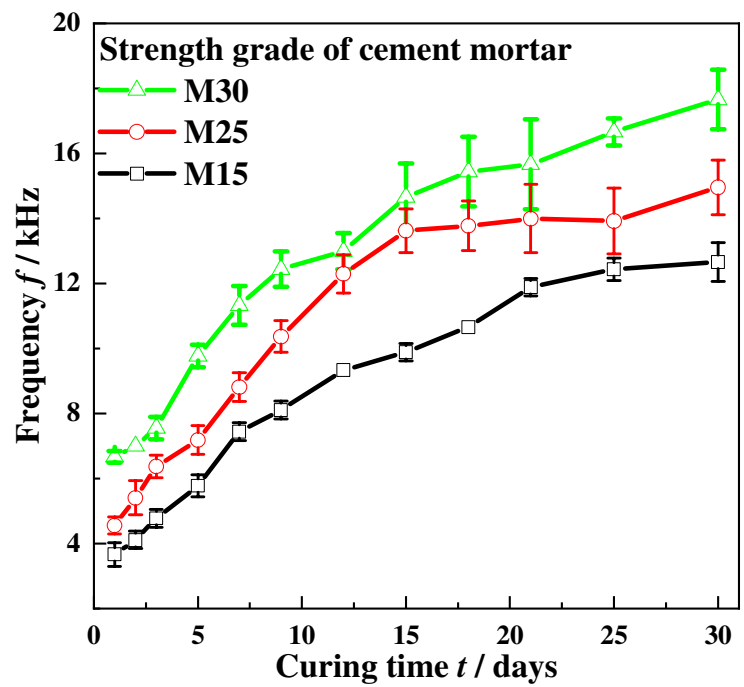

Fig. 21 Evolution of steel bar frequency with curing time of 3 type samples ( $x$ coordinate of measuring point $=25 \mathrm{~cm}$ ).

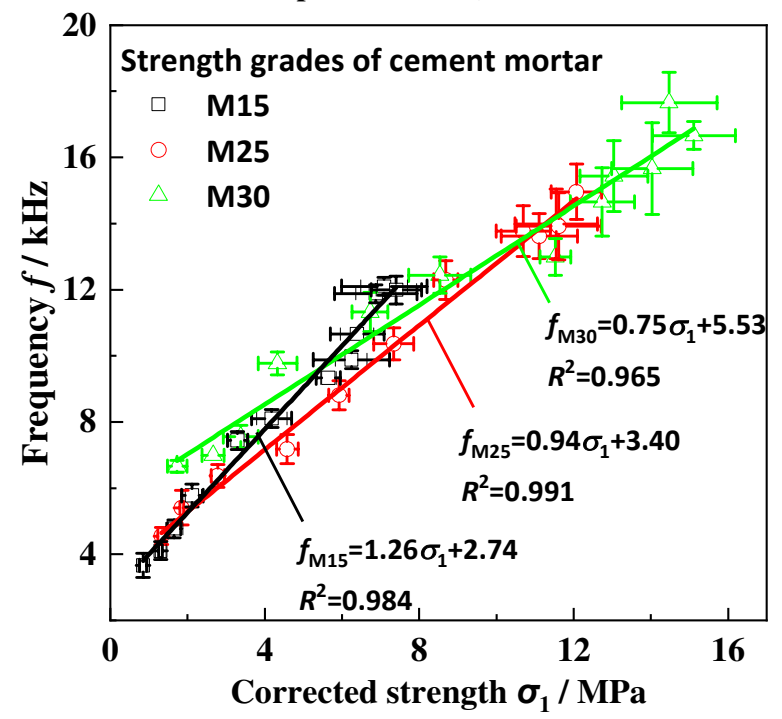

Fig. 22 Evolution of steel bar frequency with scaled strength of 3 type samples ( $x$ coordinate of measuring point $=25 \mathrm{~cm}$ ).

The relationship between the scaled strength of the frequency test samples and the vibration frequency of the steel bar was also established, as shown in Fig. 22. In general, the vibration frequency of the steel bar increases linearly with increasing strength of the test sample. This linear dependency is particularly clear when the fitting is executed on each grade, i.e., with a variance value of 0.991 for M25. An interesting point is that the slope of the fitting curves decreases with increasing strength grade, i.e., 1.26 for M15, 0.94 for M25 and 0.75 for M30. A possible explanation might be linked to the phenomenon in Section 5.3 which shows smaller scaled experimental result than the predicted result for samples of shorter curing time.

\section{Conclusions}

In this paper, a non-destructive, economical and accurate detection strength evaluation method for the steel bar cement mortar that suites for on-site using purpose has been proposed. Cement 
mortar with good homogeneity was selected as the research object. By deducing the vibration equation of steel bar in cement mortar, the correspondence between the vibration frequency of steel bar and the strength of mortar material was obtained. Next, the theoretical relationship is verified by comparing the predicted frequency with the experimental results. Extra test samples with another two aggregate ratios were studied and further proved the correspondence between the vibration frequency of the steel bar and the strength of the pouring material. The result shows that

(1) The vibration frequency of the steel bar depends on the dynamic stiffness coefficient of the cement mortar as well as the density, length, elastic modulus, inertia moment of steel bar; the parameter analysis shows that the dynamic stiffness of the cement mortar material has a dominant influence in most circumstance.

(2) The $\mathrm{PFC}^{2 \mathrm{D}}$ simulation of the SHPB experiment shows that a single-valued mapping relation exists between the dynamic stiffness coefficient and the UCS of the cement mortar sample, i.e., increased dynamic stiffness with increasing UCS.

(3) The theoretically predicted vibration frequency are compared with the experimental results and shows the consistency in the dependency on the strength of the cement mortar. The correctness of the theoretical expression of vibration frequency of the steel bar is verified.

(4) The experimental results show that the vibration frequency of the steel bar is linearly depending on the strength of the cement mortar material, regardless of varying sample size and different aggregate ratio. This makes it appropriate to use the vibration frequency of the steel bar to detect the strength of the cement mortar material.

(5) Further study needs to consider the response of the vibration frequency of the steel bar to the internal defects of the component and the influence of the steel cage.

\section{Acknowledgments}

Financial supports for this work, provided by the Fundamental Research Funds for the Central Universities (No. 2018ZDPY08), the National Natural Science Foundation of China (No. 41974164) and the Chinese Government Scholarships (No. 201906420030), are gratefully acknowledged.

\section{Author contributions}

Song Lei and Shi Hao conceived and designed the experiments; Shi Hao, Wang Guozhu and Yuan Guotao simulated the model; Shi Hao, Wang Guozhu, Yuan Guotao, Chen Guiwu, Wang Yu and Lin Gang performed the experiments; Shi Hao and Chen Whenlong analyzed the data; Shi Hao, Chen Wenlong and Song Lei wrote the paper.

\section{Conflict of interest}

The authors declare no conflict of interest.

\section{Reference}

[1] B. Youcef, K. Said, A.B. Khoudja, Prediction of concrete strength by non-destructive testing in old structures: Effect of core number on the reliability of prediction, MATEC Web of Conferences, 149(2018): 02007. https://doi.org/10.1051/matecconf/201714902007

[2] J.A. Bogas, A. Gomes, Compressive behavior and failure modes of structural lightweight aggregate concrete - Characterization and strength prediction, Mater. Design 46 (2013): 832-841. https://doi.org/10.1016/j.matdes.2012.11.004

[3] D. Breysse, J.P. Balayssac, S. Biondi, A. Borosnyoi, E. Candigliota, L. Chiauzzi, V. Garnier, M. Grantham, O. Gunes, V. Luprano, A. Masi, V. Pfister, Z.M. Sbartai, K. Szilagyi, M. Fontan, Nondestructive assessment of in situ concrete strength: comparison of approaches through an international benchmark, Mater. Struct. 50 (2017): 133. https://doi.org/10.1617/s11527-017-1009- 
[4] S. Iwata, S. Matsuno, K. Yasuda, H. Tanaka, Development of a new breakwater with steel-concrete composite cylindrical shell structure, Proceedings of the eleventh (2001) international offshore and polar engineering conference (2011): 153-159. https://www.onepetro.org/conferencepaper/ISOPE-I-01-362

[5] Z. Algin, S. Gerginci, Freeze-thaw resistance and water permeability properties of roller compacted concrete produced with macro synthetic fibre, Constr. Build. Mater. 234 (2020): UNSP 117382. https://doi.org/10.1016/j.conbuildmat.2019.117382

[6] Z.Y. Wang, High Performance Concrete in Highway Bridge in Cold and Arid Regions, Green power, materials and manufacturing technology and applications II, 214 (2012): 35-39. https://doi.org/10.4028/www.scientific.net/AMM.214.35

[7] J.A. Bogas, M.G. Gomes, A. Gomes, Compressive strength evaluation of structural lightweight concrete by non-destructive ultrasonic pulse velocity method, Ultrasonics 53 (2013): 962-972. https://doi.org/10.1016/j.ultras.2012.12.012

[8] H. Sasanipour, F. Aslani, Effect of specimen shape, silica fume, and curing age on durability properties of self-compacting concrete incorporating coarse recycled concrete aggregates, Constr. Build. Mater. 228 (2019): 117054. https://doi.org/10.1016/j.conbuildmat.2019.117054

[9] H. Sasanipour, F. Aslani, Durability properties evaluation of self-compacting concrete prepared with waste fine and coarse recycled concrete aggregates, Constr. Build. Mater. 22 (2020): UNSP 117540. https://doi.org/10.1016/j.conbuildmat.2019.117540

[10] I.A. Tijani, Y.F. Wu, C.W. Lim, Aggregate size effects and general static loading response on mechanical behavior of passively confined concrete, Constr. Build. Mater. 205 (2019): 61-72. https://doi.org/10.1016/j.conbuildmat.2019.01.164

[11] M. Zahid, N. Shafiq, A. Jalal, Investigating the effects of solarcure curing method on the compressive strength, microstructure and polymeric reaction of fly ash based geopolymer, Constr. Build. Mater. 181 (2018): 227-237. https://doi.org/10.1016/j.conbuildmat.2018.06.046

[12] ASTM C 42/C 42M-04, Standard test method for obtaining and testing drilled cores and sawed beams of concrete, West Conshohocken, PA, USA: ASTM International, 2004. https://doi.org/10.1520/C0042_C0042M-20

[13] Z. Lei, QF. Xu, X.M. Li, C.M. Zhu. Experimental studies on reinforced column capacity affected by core drilling, Adv. Mater. Res. 133-134 (2010): 1195-200. https://doi.org/10.4028/www.scientific.net/AMR.133-134.1195

[14] T. Manzur, A. Khomeni, B. Baten, K.M.A. Hossain, Investigating significance of various parameters affecting capacity of core drilled columns for safe core extraction, Eng. Struct., 200 (2019): 109722. https://doi.org/10.1016/j.engstruct.2019.109722

[15] A. Masi, D. Nigro, M. Vona, Effect of Core Drilling and Subsequent Restoration on RC Column Strength, 15 WCEE, 2012. https://www.iitk.ac.in/nicee/wcee/article/WCEE2012 5148.pdf

[16] T.Z. Xu, J. Li, Assessing the spatial variability of the concrete by the rebound hammer test and compression test of drilled cores, Constr. Build. Mater. 188 (2018): 820-832. https://doi.org/10.1016/j.conbuildmat.2018.08.138

[17] M. Alwash, D. Breysse, Z.M. Sbartai, Non-destructive strength evaluation of concrete: Analysis of some key factors using synthetic simulations, Constr. Build. Mater. 99 (2015): 235-245. https://doi.org/10.1016/j.conbuildmat.2015.09.023

[18] K. Amini, M. Jalalpour, N. Delatte, Advancing concrete strength prediction using non-destructive testing: Development and verification of a generalizable model, Constr. Build. Mater. 102 (2016): 
762-768. https://doi.org/10.1016/j.conbuildmat.2015.10.131

[19] S. Karahan, A. Buyuksarac, E. Isik, The relationship between concrete strengths obtained by destructive and non-destructive methods, IJST-T Civ. Eng. 44 (2020): 91-105. https://doi.org/10.1007/s40996-019-00334-3

[20] M. Kazemi, R. Madandoust, J. de Brito, Compressive strength assessment of recycled aggregate concrete using Schmidt rebound hammer and core testing, Constr. Build. Mater. 224 (2019): 630638. https://doi.org/10.1016/j.conbuildmat.2019.07.110

[21] H.Y. Qasrawi, Concrete strength by combined nondestructive methods - Simply and reliably predicted, Cement Concrete Res. 30 (2000): 739-746. https://doi.org/10.1016/S0008$\underline{8846(00) 00226-X}$

[22] P.G. Asteris, V.G. Mokos, Concrete compressive strength using artificial neural networks, Neural. Comput. Appl. 32 (2020), 11807-11826. https://doi.org/10.1007/s00521-019-04663-2

[23] K. Kovler, F. Wang, B. Muravin, Testing of concrete by rebound method: Leeb versus Schmidt hammers, Mater. Struct. 138 (2018). https://doi.org/10.1617/s11527-018-1265-1

[24] A. Dey, G. Miyani, S. Debroy, A. Sil, In-situ NDT investigation to estimate degraded quality of concrete on existing structure considering time-variant uncertainties, J. Struct. Eng. 27 (2020): 101001. https://doi.org/10.1016/j.jobe.2019.101001

[25] M. Alwash, D. Breysse, Z.M. Sbartaï, Non-destructive strength evaluation of concrete: Analysis of some key factors using synthetic simulations, Constr. Build. Mater. 99(2015): 235-245. http://dx.doi.org/10.1016/j.conbuildmat.2015.09.023

[26] S. Na, H.K. Lee, A technique for improving the damage detection ability of the electro-mechanical impedance method on concrete structures, Smart Mater. Struct. 21(2012): 085024. https://doi.org/10.1088/0964-1726/21/8/085024

[27] J. Kim, C. Lee, S. Park, K. Koh, Real-time strength development monitoring for concrete structures using wired and wireless electro-mechanical impedance techniques. KSCE J. Civ. Eng. 17(2013): 1432-1436. https://doi.org/10.1007/s12205-013-0390-1

[28] T. Komarkova, P. Fiala, M. Steinbauer, Z. Roubal. Testing an impedance non-destructive method to evaluate steel-fiber concrete samples, Meas. Sci. Rev. 18(2018): 35-40. https://doi.org/10.1515/msr-2018-0006

[29] S. Moharana, S. Bhalla, Development and evaluation of an external reusable piezo-based concrete hydration-monitoring sensor, J. Intel. Mat. Syst. Str. 30(2019): 2770-2788. https://doi.org/10.1177/1045389X19873414

[30] C. Bharathi Priya, T. Jothi Saravanan, K. Balamonica, N. Gopalakrishnan, A.R.M. Rao, EMI based monitoring of early-age characteristics of concrete and comparison of serial/parallel multi-sensing $\begin{array}{llll}\text { technique, } & \text { Constr. } & \text { Build. } & \text { Mater. }\end{array}$ https://doi.org/10.1016/j.conbuildmat.2018.10.079

[31] A. Thirumalaiselvi, S. Sasmal, Electro-mechanical impedance based strength monitoring technique for hydrating blended cements, Smart Struct. Syst. 65 (2020): 751-764. http://dx.doi.org/10.12989/sss.2020.25.6.751

[32] T. Oh, J. Kim, C. Lee, S. Park, Nondestructive concrete strength estimation based on Electromechanical impedance with artificial neural network, J. Adv. Concr. Technol. 15(2017): 94-102. https://doi.org/10.3151/jact.15.94

[33] D.R. Biswal, U.C. Sahoo, S.R. Dash, Non-destructive strength and stiffness evaluation of cementstabilised granular lateritic soils, Road mater. pavement 21 (2020): 835-849 
https://doi.org/10.1080/14680629.2018.1511458

[34] A.H. Lu, J.H. Xu, S.C Hu, The effect of preload force on the transverse vibration frequency of anchorage system, J. Min. Safety Eng. $34 \quad$ (2017): 684-688. https://doi.org/10.13545/j.cnki.jmse.2017.04.012(in Chinese)

[35] T. LEE, J. LEE. Setting time and compressive strength prediction model of concrete by nondestructive ultrasonic pulse velocity testing at early age, Constr. Build. Mater. 252(2020): 119027. https://doi.org/10.1016/j.conbuildmat.2020.119027

[36] M. Saleem, Assessing the load carrying capacity of concrete anchor bolts using non-destructive tests and artificial multilayer neural network, J. Struct. Eng. 30(2020): 101260. https://doi.org/10.1016/j.jobe.2020.101260

[37] J.J. Martin-del-Rio, J. Canivell, R.M. Falcon, The use of non-destructive testing to evaluate the compressive strength of a lime-stabilised rammed-earth wall: Rebound index and ultrasonic pulse velocity, Constr. $\quad$ Build. $\quad$ Mater. 242(2020): 118060. https://doi.org/10.1016/j.conbuildmat.2020.118060

[38] D. Lootens, M. Schumacher, M. Liard, S.Z. Jones, D.P. Bentz, S. Ricci, V. Meacci, Continuous strength measurements of cement pastes and concretes by the ultrasonic wave reflection method, $\begin{array}{lllll}\text { Constr. } & \text { Build. } & \text { Mater. } & \text { 242(2020): } & \text { UNSP }\end{array}$ https://doi.org/10.1016/j.conbuildmat.2019.117902

[39] J.P. Godinho, T.F. De Souza Júnior, M.H.F. Medeiros, M.S.A. Silva, Factors influencing ultrasonic pulse velocity in concrete, Revista IBRACON de Estruturas e Mater. 13(2020): 222-247. https://doi.org/10.1590/s1983-41952020000200004

[40] D.C. Xue, Research on bolting quality non-destructive testing technology and its application in Xishan mining area, China University of Mining and Technology, 2013. (in Chinese)

[41] H. Shi, H.Q. Zhang, L. Song, Y. Wu, Variation of strata pressure and axial bolt load at a coal mine face under the effect of a fault, Arch. Min. Sci. 64(2019): 351-374. https://doi.org/10.24425/ams.2019.128688

[42] M.L. Cao, Z.X. Liu, C.P. Xie, Effect of steel-PVA hybrid fibers on compressive behavior of CaCO3 whiskers reinforced cement mortar, J. Struct. Eng. 31(2020): 101314. https://doi.org/10.1016/j.jobe.2020.101314

[43] S. Siddique, J.G. Jang, Assessment of molybdenum mine tailings as filler in cement mortar, J. Build. Eng. 31(2020): 101322. https://doi.org/10.1016/j.jobe.2020.101322

[44] R. Gopalakrishnan, S. Nithiyanantham, Microstructural, mechanical, and electrical properties of copper slag admixtured cement mortar, J. Build. Eng. 31(2020): 101375. https://doi.org/10.1016/j.jobe.2020.101375

[45] O. Doeva, P.K. Masjedi, P.M. Weaver, Static deflection of fully coupled composite Timoshenko beams: An exact analytical solution, Eur. J. Mech. A-Solid. 193(2018): 295-311. https://doi.org/10.1016/j.conbuildmat.2018.10.208

[46] A. Jahangiri, N.K.A. Attari, A. Nikkhoo, Z. Waezi, Nonlinear dynamic response of an EulerBernoulli beam under a moving mass-spring with large oscillations, Arch. Appl. Mech. 90(2020): 1135-1156. https://doi.org/10.1007/s00419-020-01656-9

[47] B. Zhen, J. Xu, J.Q. Sun, Analytical solutions for steady state responses of an infinite EulerBernoulli beam on a nonlinear viscoelastic foundation subjected to a harmonic moving load, J. Sound Vib. 476 (2020): 115271. https://doi.org/10.1016/j.jsv.2020.115271

[48] M. Ansari, E. Esmailzadeh, D. Younesian, Frequency analysis of finite beams on nonlinear Kelvin- 
Voight foundation under moving loads, J. Sound Vib. 330 (2011): 1455-1471. https://doi.org/10.1016/j.jsv.2010.10.005

[49] Z. Hryniewicz, Dynamics of Rayleigh beam on nonlinear foundation due to moving load using Adomian decomposition and coiflet expansion, Soil dyn. Earthq. Eng. 31 (2011):1123-1131. https://doi.org/10.1016/j.soildyn.2011.03.013

[50] H. Fakhreddine, A. Adri, S. Rifai, R. Benamar, A multimode approach to geometrically Non-linear forced Vibrations of Euler-Bernoulli multispan beams, J. Vib. Eng. Technol. 8(2020): 319-326. https://doi.org/10.1007/s42417-019-00139-8

[51] J.Y. Wu, M.M. Feng, X.B. Mao, J.M. Xu, W.L. Zhang, X.Y. Ni, G.S. Han, Particle size distribution of aggregate effects on mechanical and structural properties of cemented rockfill: experiments and modeling, $\quad$ Constr. $\quad$ Build. $\quad$ Mater. $193(2018)$ : 295-311. https://doi.org/10.1016/j.conbuildmat.2018.10.208

[52] X.W. Guo, Q. Zhao, S.T. Gu, X. Cai, Creep property of granular materials based on viscoelastic interface between micro structural granular, Rock and Soil Mechanics 37(2016): 105-112. https://doi.org/10.16285/j.rsm.2016.S2.012

[53] L. Liu, C. Zhu, C.C. Qi, B. Zhang, K.I. Song,.A microstructural hydration model for cemented paste backfill considering internal sulfate attacks, Constr. Build. Mater. 211(2019): 99-108. https://doi.org/10.1016/j.conbuildmat.2019.03.222

[54] H. Shi, L. Song, H.Q. Zhang, K.K. Xue, G.T. Yuan, Z.S. Wang, G.Z. Wang, Numerical study on mechanical and failure properties of sandstone based on the power-law distribution of pre-crack length, Geonech. Eng. 19(2019):421-434. https://doi.org/10.12989/ gae.2019.19.5.421

[55] H. Shi, H.Q. Zhang, L. Song, Z. Yang, G.T. Yuan, X.R. Xue, Y. Wang, Failure characteristics of sandstone specimens with randomly distributed pre-cracks under uniaxial compression, Environ. Earth Sci. 79 (2020): 193. https://doi.org/10.1007/s12665-020-08933-4

[56] S. Milovanovic, L. von Sydow, A high order method for pricing of financial derivatives using Radial Basis Function generated Finite Differences, Math. Comput. Simulat. 174(2020): 205-217. https://doi.org/10.1016/j.matcom.2020.02.005

[57] Z.L. Zhou, J.Y. Lu, X. Cai, Static and dynamic tensile behavior of rock-concrete bi-material disc with different interface inclinations, Constr. Build. Mater. 256(2020): UNSP 119424. https://doi.org/10.1016/j.conbuildmat.2020.119424

[58] R.J. Wu, H.B. Li, X.F. Li, X. Xia, L.W. Liu, Experimental study and numerical simulation of the dynamic behavior of transversely isotropic phyllite, Int. J. Geomech. 20(2020): 04020105. https://doi.org/10.1061/(ASCE)GM.1943-5622.0001737

[59] Z.Y. Han, D.Y. Li, T. Zhou, Q.Q. Zhu, P.G. Ranjith, Experimental study of stress wave propagation and energy characteristics across rock specimens containing cemented mortar joint with various thicknesses, Int. J. Rock Mech. Min. 131(2020): 104352. https://doi.org/10.1016/j.ijrmms.2020.104352

[60] L. Zhu, S.C. Yu, W.B. Zhu, G.R. Feng, J.M Xu, Y.X. Guo, T.Y Qi. Dynamic loading induced by the instability of voussoir beam structure during mining below the slope, Int. J. Rock Mech. Min. 132 (2020): 104343. https://doi.org/10.1016/j.ijrmms.2020.104343

[61] B.J. Liu, J.Y. Jiang, S. Shen, F. Zhou, J.Y. Shi, Z.H. He, Effects of curing methods of concrete after steam curing on mechanical strength and permeability, Constr. Build. Mater. 256(2020): UNSP 119441. https://doi.org/10.1016/j.conbuildmat.2020.119441

[62] H. Maghsoodloorad, H. Khalili, A. Allahverdi, Alkali-activated phosphorous slag performance 
under different curing conditions: compressive strength, hydration products, and microstructure, J. Mater. Civil. Eng. 30(2018): 04017253. https://doi.org/10.1061/(ASCE)MT.1943-5533.0002101

[63] H. Wang, T. Du, A.L. Zhang, P. Cao, L.C. Zhang, X.J. Gao, J.Z. Liu, FT. Shi, Z.M. He, Relationship between electrical resistance and rheological parameters of fresh cement slurry, Constr. Build. Mater. 256(2020): UNSP 119479. https://doi.org/10.1016/j.conbuildmat.2020.119479

[64] F. Di Pietro, J. Fernandez, G. Migoni, E. Kofman, Mixed-mode state-time discretization in ODE numerical integration, J. Comput. Appl. Math. 337(2020): 112911. https://doi.org/10.1016/j.cam.2020.112911

[65] C.X. Zhang, L.L. Wang, H. Zhu, H.W. Tang, Integrated hydrodynamic model for simulation of river-lake-sluice interactions, Appl. Math. Model. 83(2020): 90-106. https://doi.org/10.1016/j.apm.2020.02.019

[66] M.C. Villeneuve, M.J. Heap, A.R.L. Kushnir, T. Qin, P. Baud, G.L. Zhou, T. Xu, Estimating in situ rock mass strength and elastic modulus of granite from the Soultz-sous-Forts geothermal reservoir (France), Geotherm. Energy 6(2018): UNSP 11. https://doi.org/10.1186/s40517-018-0096-1

[67] H. Shi, H.Q. Zhang, L. Song, Evolution of sandstone shear strength parameters and its mesoscopic mechanism, Geomech. Eng. 20(2020): 29-41. https://doi.org/10.12989/gae.2019.20.1.029

[68] S.C. Chen, Z.H. Zhao, Y.D. Chen, Q. Yang, On the effective stress coefficient of saturated fractured rocks, Comput. Geotech. 123(2020): 103564. https://doi.org/10.1016/j.compgeo.2020.103564

[69] A. Prashant, D. Bhattacharya, S. Gundlapalli, Stress-state dependency of small-strain shear modulus in silty sand and sandy silt of Ganga, Geotechnique 69(2019): 42-56. https://doi.org/10.1680/jgeot.17.P.100

[70] Q. Li, G.P. Steven, O.M. Querin, Y.M. Xie, Stress based optimization of torsional shafts using an evolutionary procedure, Int. J. Solids Struct. 38(2001): 5661-5677. https://doi.org/10.1016/S0020$\underline{7683(00) 00365-6}$

[71] G. Ramm, H. Moser, A. Braun, A new scheme for Generating and Measuring active, reactive, and apparent power at power frequencies with uncertainties of $2.5 \times 10^{-6}$, IEEE Trans. Instrum. Meas. 48(1999):422-426. https://doi.org/10.1109/19.769616

[72] R. Capozucca, Vibration analysis of damaged RC beams strengthened with GFRP. Compos. Struct. 200(2018): 624-634. https://doi.org/10.1016/j.compstruct.2018.05.112

[73] X.L. Zhang, H.L. Yue, Z.M. Li, J.L. Xu, B.C. Wen, Stability and coupling dynamic characteristics of a vibrating system with one internal degree of freedom and two vibrators, Mech. Syst. Signal Pr. 143(2020): 106812. https://doi.org/10.1016/j.ymssp.2020.106812

[74] J.Q. Shi, G.Q. Si, S.W. Li, B, Oresanya, Y.B. Zhang, Feature extraction based on the fractional Fourier transform for vibration signals with application to measuring the load of a tumbling mill, Control Eng. Pract. 84 (2019): 238-246. https://doi.org/10.1016/j.conengprac.2018.11.012

[75] H. Qayyum, M. Majid, S.M. Anwar, B. Khan, Facial expression recognition using stationary wavelet transform features, Math. Probl. Eng. 2017(2017): 9854050. https://doi.org/10.1155/2017/9854050

[76] D. Abboud, Y. Marnissi, M. Elbadaoui, Optimal filtering of angle-time cyclostationary signals: Application to vibrations recorded under nonstationary regimes, Mech. Syst. Signal Pr. 145(2020): 106919. https://doi.org/10.1016/j.ymssp.2020.106919

[77] N. Wulan, W. Wang, P.Z. Sun, K.Q. Wang, Y. Xia, H.G. Zhang, Generating electrocardiogram signals by deep learning, Neurocomputing 404(2020): 122-136. https://doi.org/10.1016/j.neucom.2020.04.076 
[78] V.K. Tiwari, A.C. Umarikar, T. Jain, Fast amplitude estimation of harmonics using undecimated wavelet packet transform and its hardware implementation, IEEE T Instrum. Meas. 67(2018): 6577. https://doi.org/10.1109/TIM.2017.2759358

[79] Y.F. Li, Z.N. Han, Z.J. Wang, Research on a signal separation method based on vold-kalman filter of improved adaptive instantaneous frequency estimation, IEEE Access 8(2020): 112170-112189. https://doi.org/10.1109/ACCESS.2020.3002999

[80] Y.C. Li, S.Y. Sun, C.A. Tang, Analytical prediction of the shear behaviour of rock joints with quantified waviness and unevenness through wavelet analysis, Rock Mech. Rock Eng. 52(2019): 1-13. https://doi.org/10.1007/s00603-019-01817-5

[81] S. Tamborski, K. Wrobel, M.M. Bartuzel, M. Szkulmowski, Spectral and time domain optical coherence spectroscopy, Opt. Laser. Eng. 133(2020): UNSP 106120. https://doi.org/106120.10.1016/j.optlaseng.2020.106120

[82] V.V. Brazhkin, I.M. Suslov, Mechanism of universal conductance fluctuations, J. Phys-Condens. Mat. 32(2020): 35LT02. https://doi.org/10.1088/1361-648X/ab8ec5

[83] Q.J. Yang, X.X. Qu, High-precision harmonic analysis algorithm based on five-term msd secondorder self-convolution window four-spectrum-line interpolation, Mobile Netw. Appl. 2020. https://doi.org/10.1007/s11036-020-01606-3

[84] S.R. Konatham, R. Maram, L.R. Cortes, J.H. Chang, L. Rusch, S. LaRochelle, H.G. de Chatellus, J. Azana, Real-time gap-free dynamic waveform spectral analysis with nanosecond resolutions through analog signal processing, Nat. Commun., 11(2020): 3309. https://doi.org/10.1038/s41467020-17119-2

[85] K.N.R.S.V. Prasad, K.B. D'souza, V.K. Bhargava, A downscaled faster-renn framework for signal detection and time-frequency localization in wideband RF systems, IEEE T. Commun. 19(2020): 4847-4862. https://doi.org/10.1109/TWC.2020.2987990

[86] J.A.M. Carrer, R.F. Scuciato, L.F.T. Garcia, The boundary element method applied to the analysis of Euler-Bernoulli and timoshenko continuous beams, IJST-T. Civ. Eng. (2020). https://doi.org/10.1007/s40996-020-00359-Z

[87] E. Bosco, R.J.M.A. Claessens, A.S.J. Suiker, Multi-scale prediction of chemo-mechanical properties of concrete materials through asymptotic homogenization, Cement Concrete Res. 128(2020): 105929. https://doi.org/10.1016/j.cemconres.2019.105929

[88] Y.G. Li, H.M. Zhang, G.X. Liu, D.W. Hu, X.R. Ma, Multi-scale study on mechanical property and strength prediction of aeolian sand concrete, Constr. Build. Mater. 247(2020): UNSP 118538. https://doi.org/10.1016/j.conbuildmat.2020.118538

[89] K.H. Li, Y.M. Cheng, Z.Y. Yin, D.Y. Han, J.J. Meng, Size Effects in a Transversely Isotropic Rock Under Brazilian Tests: Laboratory Testing, Rock Mech. Rock Eng. 2020. https://doi.org/10.1007/s00603-020-02058-7

[90] H. Zhai, H. Masoumi, M. Zoorabadi, I. Canbulat, Size-dependent Behaviour of Weak Intact Rocks, Rock Mech. Rock Eng. 2020. https://doi.org/10.1007/s00603-020-02117-z

[91] L.E. Kosteskia, I. Iturriozb, G. Lacidognac, A. Carpinterid, Size effect in heterogeneous materials analyzed through a lattice discrete element method approach, Eng. Fract. Mech. 232(2020): 107041. https://doi.org/10.1016/j.engfracmech.2020.107041

[92] H.Q. Zhang, H. Shi, Y. Wu, H. Pu, Numerical statistical analysis on self-organizing behavior of microfracturing events in rock failure, Int. J. Distrib. Sens. N. 14(2018): 1550147718768993. https://doi.org/10.1177/1550147718768993 
[93] L. Huang, Z.J. Chen, H.L Ye, A mechanistic model for the time-dependent autogenous shrinkage of high performance concrete, Constr. Build. Mater. 225(2020). https://doi.org/10.1016/j.conbuildmat.2020.119335

[94] E. Hoek, E.T. Brown, Underground excavations in rock. Institution of Mining and Metallurgy, London 1980. https://doi.org/10.1016/0148-9062(81)90809-3

[95] L.K. Varga, J. Kovac, L. Novak, Determination of external and internal demagnetizing factors for strip-like amorphous ribbon samples, J Magn Magn Mater. 507(2020): 166845. https://doi.org/10.1016/j.jmmm.2020.166845

[96] L.Z. Ye, X.J. Zhu, Y. He, X.M. Wei, Ultrasonic cavitation damage characteristics of materials and a prediction model of cavitation impact load based on size effect, Ultrason. Sonochem. 66(2020): 105115. https://doi.org/10.1016/j.ultsonch.2020.105115 